\title{
Do Criminally Accused Politicians Affect ECONOMic Outcomes? Evidence From India
}

\author{
Nishith Prakash \\ University of Connecticut*
}

\author{
Marc Rockmore \\ Clark University ${ }^{\dagger}$ \\ March, $2017^{\S}$
}

\author{
Yogesh Uppal \\ Youngstown State University $\ddagger$
}

\begin{abstract}
We study the causal impact of electing criminally accused politicians to state legislative assemblies in India on the subsequent economic performance of their constituencies. Using data on the criminal background of candidates running for state assembly elections and a constituency-level measure of economic activity proxied by intensity of night-time lights, we employ a regression discontinuity design that controls for unobserved heterogeneity across constituencies and find 22-percentage point lower yearly growth in the intensity of night-time lights arising from the election of a criminally accused politician. These effects are driven by serious, financial and the number of criminal charges and appear to be concentrated in the less developed and more corrupt Indian states. Similar findings emerge for the provision of public goods using data on India's major rural roads construction program.
\end{abstract}

JEL Classification: D72, D73, O40, O12

Keywords: Criminal Accusations, Politicians, Night-time Lights, Regression Discontinuity, India

*Nishith Prakash: Assistant Professor, Department of Economics and Human Rights Institute, University of Connecticut, IZA, CReAM, HiCN \& INSIDE, Storrs, CT 06269, USA (e-mail: nishith.prakash@uconn.edu).

${ }^{\dagger}$ Marc Rockmore: Assistant Professor, Department of Economics, Clark University \& HiCN, Worcester, MA 01610, USA (e-mail: mrockmore@clarku.edu).

†Yogesh Uppal: Associate Professor, Department of Economics, Youngstown State University, Youngstown, $\mathrm{OH}$ 44406, USA (e-mail: yuppal@ysu.edu).

${ }^{\S}$ This project greatly benefited from financial and logistical support from the International Growth Center for the research as well as its dissemination. We thank Chris Barrett, Thushyanthan Baskaran, Sonia Bhalotra, Prashant Bharadwaj, Areendam Chanda, Alex Cohen, Eric Edmonds, Irma Clots Figueras, Teevrat Garg, Clement Imberts, Lakshmi Iyer, Tarun Jain, Dean Karlan, Daniel Keniston, Erzo Luttmer, Vikram Maheshri, Mushfiq Mobarak, Dilip Mookherjee, Ameet Morjaria, Karthik Muralidharan, Sriniketh Nagavarapu, Stephen Ross, Nick Ryan, Sandip Sukhtankar, Chris Udry, Gergely Ujhelyi and seminar participants at Brigham Young University, Carlton University, Cornell University, City College of New York, Dartmouth College, Delhi School Winter School 2015, Georgia Tech University, Indian School of Business, Indian Statistical Institute, Lehigh University, Penn State Harrisburg, University of Connecticut, University of Georgia, University of Michigan, University of North Dakota, University of Rhode Island, Wellesley College, Wesleyan University, Yale University, 12th Midwest International Economic Development Conference, 10th Annual Conference on Economic Growth and Development, and BIGD Conference on Political Economy, Accountability and Governance for helpful comments and discussions. We especially thank to Shilpa Aggarwal, Oliver Vanden Eynde, Raymond Fisman, Dan Keniston, and Brian Min for sharing data and Rajyabardhan Sharma (ex-Indian Police Service) for helping us understand the Indian Penal Code and the ADR Criminal accusation data. We also thank Tasneem Ahmed, Maxwell Aliapoulios, Kirtan Bhavsar, Doga Akar Bilgin, Rachel Borden, Avijit Ghosh, Kelsey Barton-Henry, Sungoh Kwon, Christopher McCormack, Sharon Pallier, Andrew Pitt, Brain Tiedt, Qinghan Yan who provided excellent research assistance. We are responsible for any errors that may remain. A previous version of the paper was circulated with the title: "Do Criminal Representatives Hinder or Improve Constituency Outcomes? Evidence from India". 
"They may protest the administrative machinery and thereby break the law, but they are seen as local heroes who are trying to help poor people by different means" - (NY Times, 2014)

"Earlier politicians used criminals. Now the criminals themselves have entered politics" - (Associated Press, 2014)

\section{Introduction}

Despite a history of widely contested and transparent elections, and the presence of a vibrant and open media, India elects an ever-increasing number of politicians facing criminal charges. The share of Members of Parliament, the national legislature, who face pending criminal charges has risen from 24 percent in 2004 to 34 percent in 2014 (NY Times 2014) [ While the election of criminally accused candidates to public office is concerning in any context, this is especially true for India. Large quantities of funds are distributed by the government through a wide variety of interventions and programs, which have been plagued by costly scandals with estimated losses in the hundreds of billions of dollars (Sukhtankar and Vaishnav 2015) $!^{2}$ This problem is exacerbated by a severely understaffed judiciary and police force, resulting in an extremely slow judicial system ${ }^{3}$ Taken together, these realities create a context in which an influx of criminally accused politicians could be especially costly for an economy.

In this paper, we examine the aggregate economic costs of electing criminally accused politicians to State Legislative Assemblies (Vidhan Sabhas) in India for elections held during the 2004 to 2008 period. It is generally accepted, both in the literature and in public debate, that the election of criminally accused candidate is likely to have substantial economic costs for a constituency. Despite this widespread belief of an adverse effect, no formal estimates exist. We take advantage of a Supreme Court of India order in 2003 which required all candidates seeking election to the Parliament of India

\footnotetext{
${ }_{1}^{1}$ http://india.blogs.nytimes.com/2014/05/23/in-the-newly-elected-indian-parliament-worrying-trends/ ?_r $=0$.

${ }^{2}$ Looking at a statutory wage increase for participants in India's employment guarantee scheme (NREGS), Niehaus and Sukhtankar (2013) estimate marginal leakage of almost 100\%. Similarly, Baskaran et al. (2015), Nagavarapu and Sekhri (2013), and Min and Golden (2014) find that the allocation of electricity is distorted by political incentives.

${ }^{3}$ For instance, Suhkatankar and Vaishnav (2015) note that nearly 60 percent of police positions are unfilled in Uttar Pradesh. Nationwide, 20 to 30 percent of district, subordinate and High court seats are unfilled and close to a quarter of all cases have been pending for 5 years or more and there is a backlog of over 31 million cases.
} 
or to State Legislative Assemblies to disclose information on their criminal background in a sworn affidavit submitted to the Election Commission of India (ECI). The data from these affidavits not only allow us to identify criminally charged candidates, but also allow to differentiate candidates by the types and number of charges.

We measure constituency-level economic activity using satellite data on the intensity of night-time lights, since no GDP data are available for the state assembly constituencies. Night-time lights data have been used as a robust proxy for economic activity and measures of micro-development (Bleakley and Lin 2012, Henderson et al. 2012, Hodler and Rashky 2014, Michalopoulos and Papaioannou 2013, 2014, Pinkovskiy 2013, Storeygard 2014) at both the national and sub-national levels and offer several advantages $4^{4}$ First, unlike large household and economic surveys in India, night-time lights data are available at a highly disaggregated geographical level and can be aggregated to compile constituency-level measures. Second, these data are available annually, thus allowing for a more credible time series analysis. Third, night-time lights data are collected automatically by satellites and are therefore less prone to biases that may be present in administrative data.

An important challenge in this setting is to account for the unobserved heterogeneity between constituencies that elect criminally accused candidates and those that do not. For instance, criminally accused candidates may be more likely to run (and win) from certain constituencies than others. Therefore, constituencies that elect criminally accused candidates may not be comparable to those that elect non-accused candidates. Using a regression discontinuity design that credibly identifies the effect of electing criminally accused politicians by comparing constituencies which elect criminally accused with those which elect non-accused politicians in close elections, we find that electing a criminally accused politician has a large negative effect on economic activity in their constituency. On average, constituencies in which a criminally accused candidate barely won experienced roughly 22-percentage point lower yearly growth in the intensity of night-time lights than those constituencies which barely elected a non-accused candidate. Moreover, these effects are larger for politicians accused of serious or financial criminal charges. Using existing estimates from the literature on the elasticity of GDP growth to night-time lights growth, this is roughly equivalent to roughly 2.3-6.5

\footnotetext{
${ }^{4}$ Pinkovskiy and Sala-i-Martin (2016) provides a literature review of the nighttime lights measure and propose a data-driven method to assess the relative quality of GDP per capita and survey means by comparing them to the evolution of satellite-recorded nighttime lights. Michalopoulos and Papaioannou (2013) cross-validate the satellite light density and regional development by examining the relationship between luminosity and economic performance using micro-level data from the Demographic and Health Surveys.
} 
percentage point lower GDP growth per year. We further find that the negative impact varies by state characteristics. In particular, the costs are more pronounced in states with high corruption levels, lower levels of development and plausibly weaker institutions (so-called 'BIMAROU' states).

We find very similar effects using a proxy for public good provision: the roads built annually under the Pradhan Mantri Gram Sadak Yojana (PMGSY) program. The length (in kms) of roads built annually under the PMGSY is significantly lower in constituencies in which an accused politician barely won compared to constituencies in which a non-accused barely won (we discuss this in Section 6). Overall, these results highlight the high aggregate economic costs of electing lower quality politicians (i.e. criminally accused) and point to likely significant individual costs in foregone access to public services.

Our paper contributes to several related literatures. Most narrowly, our findings contribute to the emerging literature on criminally accused politicians in India. Existing studies typically focus on the selection of these candidates; some examine the response of voters to information on criminal status or criminal charges and the potential mitigating effect of caste politics (Banerjee et al. 2014, Charchard 2014). Others examine the selection of these candidates by political parties (Aidt et al. 2012, Tiwari 2014, Vaishnav 2011a, 2011b, 2011c). However, this growing body of literature on preferences over politician type and how to fight the selection of corrupt politician implicitly assumes that such politicians are less desirable for their constituencies, although the actual effect is unknown. Our study provides the first evidence of the aggregate economic cost of electing criminally accused politicians $5^{5}$ Since criminally accused politicians are not limited to India, this indicator may also be more broadly applicable (for e.g. Brazil and Pakistan) ${ }^{6} 7$

Additionally, we contribute to the discussion regarding whether criminal accusations are 'too noisy' a signal to be useful for research or policy. In part, this concern arises since political rivals may have the incentive and means to fabricate charges against opponents. Similarly, there are examples of political activists being charged while participating in democratic protests (Jaffrelot and Verniers 2014). We find that accusations can provide useful information regarding politicians as the economic costs vary with the type and the number of criminal charges.

\footnotetext{
${ }^{5}$ Chemin (2012) shows that the election of accused politicians has distributional impacts by reducing the per capita expenditure of SC, ST, and OBC members. However, he does not investigate the overall effects.

${ }^{6}$ Almost 200 legislators, or a third of Brazil's Congress, are facing charges in trials overseen by the Supreme Federal Tribunal (see: http://www. law360.com/articles/457373/brazil-has-had-it-with-corporate-bribery).

${ }^{7}$ Criminality and politics in Pakistan (see: http://www. dawn. com/news/1200870).
} 
We also make a modest contribution to the literature on the quality of politicians which typically uses proxies such as education (Alcantara 2008, Besley et al. 2005, De Paola and Scoppa 2010, Martinez-Bravo 2014) and, more recently, personality (Callen et al. 2015). As our results demonstrate, whether or not a politician is criminally accused can have an important effect on the constituency level economic outcomes. Consequently, we believe that this may represent a preelection indicator of candidate quality.

Finally, although our study focuses on India, it contributes to the broader understanding of the costs of electing lower quality politicians in clientelistic democracies. We find that the costs of electing criminally accused politicians are concentrated in states that are less developed and have higher levels of corruption. These findings are consistent with papers that suggest that low quality politicians (such as criminals) may provide targeted benefits to certain voters (Chandra 2004, Vaishnav 2011a, Banerjee and Pande 2007) based on certain salient factors, such as caste, ethnicity or class. Robinson and Verdier (2013) and van de Walle (2005) further suggest that less developed countries are associated with this type of clientelist or patronage politics. Bardhan and Mookherjee (2012) note that patronage democracies can lead to excessively short-term payoffs and a lack of long run investmetns, included the provision of public goods. In such democracies, criminally accused politicians may be especially detrimental for economic development and public goods delivery.

The remainder of this paper is organized as follows. In Section 2 we provide the background on the elected representatives in India and discuss the corruption and criminality in Indian politics. Section 3 discusses the empirical strategy, followed by the data description and the validity of the regression discontinuity design in Section 4. We present the impact of electing criminally accused politicians on night-lights in Section 5. Section 6 estimates the impact of electing criminally accused on a measure public good-roads construction, and Section 7 calculates the effect on GDP. We present variety of robustness checks in Section 8, and conclude the paper in Section 9. 


\section{Background}

\subsection{Elected Representatives in India}

India is a federal republic with a parliamentary system of government. The Parliament of India, the national level legislature, consists of two Houses-an Upper House (also called the Rajya Sabha or the Council of States) and a Lower House (also called the Lok Sabha or the House of the People). Those elected or nominated to either House of the Parliament are referred to as Members of Parliament (or MPs). State assemblies in India follow a similar structure where the Upper House is called the Legislative Council (or Vidhan Parishad) and the Lower House is called the Legislative Assembly (or Vidhan Sabha). Those elected to the state Legislative Assembly are referred to as Members of the Legislative Assembly (or MLAs). Similar to the national level, the election system at the state level is a "first-past-the-post" system and constituencies are divided into single member constituencies. The term of each MLA is 5 years, although it is possible to have elections before the 5-year term mostly due to shifting of political alignments. The focus in this paper is on the members elected to the state legislative assemblies.

The Indian Constitution grants elected representatives certain responsibilities. In particular, MLAs hold legislative, financial, and executive power. In addition to these constitutional powers, they also have control over the state bureaucracy, especially in promotions and job assignment/transfers (Asher and Novosad 2015, Iyer and Mani 2012, Krishnan and Somanathan 2013, Nath 2014, Sukhtankar and Vaishnav 2015) of funds for various development projects, distribution of licenses, and facilitate access to governmental schemes through the bureaucratic machinery. Collaboration with or control of the bureaucracy also allows politicians to act as mediators between the private sector and the government, and to lobby political allies and business contacts to bring projects to their constituencies (Bussell 2012, Chopra 1996, Jensenius 2013). Finally, MLAs also have access to discretionary development funds through the Member of Legislative Assembly Constituency Development Scheme which they can spend on development projects within their constituencies. Therefore, elected representatives can

\footnotetext{
${ }^{8}$ The nexus between politicians and bureaucrats, and in particular, the possibility of bribes involving job assignments/transfer of bureaucrats was recently alleged in a press conference on May 22, 2015 by the Chief Minister of Delhi (http://www.ndtv.com/video/player/news/ kejriwal-says-centre-has-betrayed-people-of-delhi-by-siding-with-lieutenant-governor/368367) .
} 
both directly and indirectly affect economic activity in their constituencies.

\subsection{Corruption and Criminality in Indian Politics}

Elected officials are widely reputed to be involved in corruption, mostly the graft and embezzlement of public funds (BBC News India 2012, India Today 2012). A recent paper by Sukhtankar and Vaishnav (2015) compiled an inventory of the biggest public corruption scandals uncovered after 2003, and found amounts totaling hundreds of billions of dollars.$^{9}$ Fisman et al. (2014) utilize the asset disclosures of candidates for Indian state legislators and compare the asset growth of election winners versus runners-up to calculate the financial returns from holding public office relative to the private sector opportunities available to political candidates. They find that the estimated annual growth rate of the winners' assets is 3-5 percent higher than those of the runners-up. Similarly, Bhavnani (2012) compares the change in winners' and losers' self-declared family assets in India's two most recent state and national elections, and finds that the average election winner increased their assets by $4-6$ percent a year 10

The issue of criminally accused candidates contesting elections in India is not new and has been debated at the highest level by the Election Commission of India, and the Indian Parliament. Even the Supreme Court of India showed serious concern about the increasing "criminalization" of politics, leading to its landmark judgment which made the criminal backgrounds of politicians public. In 2003, the Supreme Court of India required candidates seeking election to the Parliament or to a Legislative Assembly to file sworn affidavits detailing information on their professional and educational qualifications, their assets and liabilities and those of their immediate family, and their criminal convictions and charges. In particular, the affidavits require candidates to report prior convictions and any pending accusations for which the offence is punishable with imprisonment for two years or more, and in which a charge is framed or cognizance is taken by the Court of Law (that is, any criminal indictment). These charges are limited to those framed prior to the six-month period

\footnotetext{
${ }^{9}$ Table 1 of Sukhtankar and Vaishnav (2015) estimates a mean scam "value" of Rs. 36,000 crore (about 5.6 billion USD), and a median of Rs. 12,000 crore (about 1.9 billion USD).

${ }^{10}$ According to Banerjee et al. (2011(, in the case of Uttar Pradesh state legislators, the 287 elected MLAs in 2007 who ran for elections again in 2012 witnessed an increase in their average asset value from $\$ 220,613$ to $\$ 658,804$ over their 5 year term in office. At that time, the average annual salary of MLAs in Uttar Pradesh was approximately $\$ 12,000$. The political affiliation was especially important as MLAs who belonged to the political party heading the state government (or the ruling party) saw their asset value increase by an average of $\$ 500,000$. For opposition party members, this increase amounted to less than $\$ 300,000$.
} 
preceding an election. Since candidates face penalties for lying on the sworn affidavits and since rival candidates (and the media) have incentives to verify information contained in these affidavits, any deliberate misreporting should be minimized 11

The Association for Democratic Reforms (ADR), an election watchdog, along with the National Election Watch have conducted so-called Election Watches for all state and federal elections since 2003 in India. 12 Surprisingly, the percentage of MPs facing criminal charges has increased between the 2009 and 2014 elections for the national Parliament. The findings are similar for the state assembly elections. According to the ADR report, over 30 percent of the MLAs currently face criminal cases 13

\section{Regression Discontinuity Design}

A key contribution of this paper is the identification of causal effect of electing criminally accused politicians to state assemblies in India on constituency level economic activity. The main challenge in doing this is that the victory of criminally accused politicians is not necessarily random; for example, criminally accused candidates may be more likely to run and win from certain constituencies than others in ways that are unobservable to us. As a result, average differences in economic activity between constituencies that elected an accused MLA and those that elected a non-accused MLA will result in a biased estimate of the effect of electing criminally accused candidates.

A regression discontinuity (RD) design (Lee 2008, Imbens and Lemieux 2008) allows us to exploit a discontinuity in the treatment assignment to identify the causal effect of a treatment variable 14 In our setting, the assignment of treatment, whether a candidate is criminally accused or

\footnotetext{
${ }^{11}$ These are sworn affidavits and there is a penalty for filing incorrect affidavit (e.g. disqualification, imprisonment for a term which may extend to six months, or a fine, or both). The affidavits can be accessed from the ECI's website (http://eci.nic.in/eci/eci.html) and its website on candidate affidavit (http://eci.nic.in/eci_main1/ LinktoAffidavits.aspx).

${ }^{12}$ An Election Watch comprises of background reports based on Criminal, Financial, Educational and Income Tax details of Candidates and Winners (MPs, MLAs and Ministers) who have contested Elections to State Assemblies, the Parliament and a few local bodies.

${ }^{13}$ For example, in one of most populous and politically important state, Uttar Pradesh, 575 of the candidates for the 403 assembly seats had criminal backgrounds or faced criminal charges during the 2007 state legislative assembly elections. Out of these, 140 won the assembly seats. Unsurprisingly, following this success, an even greater number of criminally accused candidates (759) ran in the subsequent elections in 2012 . Of these, 189 won seats in the state assembly (ADR, 2012a).

${ }^{14}$ The seminal paper by Lee (2008) exploits a regression discontinuity design using electoral data. Studies using a similar design in the context of India and elsewhere include Asher and Novosad (2014), Bhalotra et al. (2013), Bhalotra and Clots-Figueras (2014), Broockman (2014), Clots-Figueras (2011, 2012), Fisman et al. (2014), and Uppal (2009).
} 
not $(A C C U S E D)$, is determined solely on the basis of a cutoff value, $\mathrm{c}=0$, of the forcing variable, the victory margin $(M A R G I N)$. The treatment assignment follows a known deterministic rule, $A C C U S E D=1(M A R G I N \geq 0)$, where $1($.$) is the indicator function. The constituencies which$ fall below the cutoff $(M A R G I N<0)$, the control group $(A C C U S E D=0)$, elect a non-accused candidate who won against an accused runner-up, and the victory margin in these elections is the difference between the vote shares of the accused runner-up and the non-accused winner. Constituencies that fall above the cutoff $(M A R G I N \geq 0)$, the treatment group $(A C C U S E D=1)$, elect a criminally accused candidate who won against a non-accused runner-up, and the victory margin in these elections is the difference in vote shares of the accused winner and the non-accused runner-up. Therefore, at the victory margin of zero, the accusation status of a politician changes discontinuously from non-accused to criminally accused. Thus, as the victory margin becomes arbitrarily small (i.e. as we move closer to the cutoff), the outcome of an election is as good as random. As a result, constituencies that barely elected a non-accused politician in a close election serve as a valid counterfactual for constituencies that barely elect a criminally accused politician.

We consider the following specification for estimating the RD treatment effect of electing a criminally accused candidate to state legislative assemblies relative to a non-accused candidate:

$$
\operatorname{GROWTH}_{i, s, t+1}=\alpha_{s}+\beta_{t+1}+\gamma A C C U S E D_{i, s, t}+f\left(M A R G I N_{i, s, t}\right)+\mu_{i, s, t+1}
$$

$\forall M A R G I N_{i, s, t} \in(c-h, c+h)$

where $G R O W T H_{i, s, t+1}$ is the yearly growth rate in night-time lights, our primary outcome of interest. This is measured as the difference in the natural log of night-time lights intensity for the constituency between the current and the previous period, for e.g. $\left[\log \left(Y_{i, s, t+1}\right)-\log \left(Y_{i, s, t}\right)\right]$, also widely accepted in the literature as a proxy for economic activity. We do not include the night light measure for the year of election as it could be driven by the previous candidate in our specification. $\alpha_{s}$ is the state fixed effects and control for any time-invariant state characteristics.

We follow Henderson et al. (2012) and Chen and Nordhaus (2011) by including year fixed effects $\beta_{t+1}$ in our estimating equation to control for contemporaneous shocks affecting all units in a year, including any factors that may affect the overall brightness detected by a sensor in any given year. In addition, the year fixed effects also controls for any macroeconomic shocks or national 
policies that affected all states uniformly. In robustness tests, we also use year-state interaction to control for any state-level economic trends or policies. The variable $A C C U S E D_{i, s, t}$ is the treatment, $M A R G I N_{i, s, t}$ is the forcing variable, and $h$ is the neighborhood around the cutoff $c=0$, also referred to as the bandwidth. The control function $f\left(M A R G I N_{i, s, t}\right)$ is some continuous function, usually a $n$-order polynomial in the forcing variable on each side of $c$. Finally $\mu_{i, s, t+1}$ is the error term. The coefficient of primary interest $\gamma$ estimates the causal impact of electing criminally accused politicians to state assemblies in India on economic activity as proxied by the growth of night-time lights. The identification of this causal effect relies on fairly weak conditions on the conditional distribution of the error term $\mu$, which is assumed to be a continuous function of the forcing variable $(M A R G I N)$.

We estimate a local linear regression (Hahn, Todd, and Van der Klaauw 2001, Porter 2003, Imbens and Lemieux 2008) as it allows for a suitable bandwidth with a linear control function. ${ }^{15}$ Our preferred bandwidth specification follows the optimal bandwidth algorithm proposed by Imbens and Kalyanaraman (2012) [referred to as IK $(h)$ ]. As a robustness check, we also estimate the local linear regression using the optimal bandwidth proposed by Calonico, Cattaneo and Titiunik (2014), half the optimal bandwidth (h/2), and twice the optimal bandwidth (2h). Since growth in night-time lights is likely to be correlated over time within a constituency, the standard errors are clustered at the constituency level.

\section{Data Description and Validity of the RD Design}

\subsection{Night-time Lights as a Measure of Economic Activity}

To study the costs associated with electing criminally accused candidates, we need a measure of economic activity at the state assembly constituency level, our unit of analysis. To the best of our knowledge, no such data exist in India. ${ }^{16}$ Large surveys, such as the National Sample Survey, the India Human Development Survey, and the Economic Census of Firms are only available at the

\footnotetext{
${ }^{15}$ Different variations of equation (1) with different bandwidths and control function have been used in the literature. For example. Lee et al. (2004) use parametric regression-based higher order polynomials in the control function (second-order, third-order, and fourth-order polynomials), thus allowing all the observations to be used in the RD estimation. However, this method puts equal weight on observations far from the cutoff, which can be misleading (Gelman and Imbens 2014).

${ }^{16}$ Although we could in principle use the Census of India to look at various measures of public goods, it is only available for the years 2001 and 2011, and therefore will not allow us to look at the annual change in outcome measures at the state assembly constituency level.
} 
district level. These cannot be used for three reasons. First, the number of constituencies varies across districts and there is no logical way to weight constituencies within districts ${ }^{17}$ Second, even if a constituency level measure of economic activity could be derived, the above mentioned surveys are not available annually. Third, these surveys only capture measures of income and consumption at the district level.

We use data on the intensity of night-time lights as a proxy for economic activity. Recent contributions of Henderson et al. (2012), Hodler and Rashky (2014), Michalopoulos and Papaioannou (2013, 2014), and Storeygard (2014) and previous work of Elvidge et al. (1997) finds the use of nighttime lights data as a useful proxy for development for regional analysis in countries with poor quality income data. $\sqrt{18}^{19}$ Results from Doll et al. (2006) and Pinkovskiy (2013) shows that light density at night is a robust proxy of economic activity. More recently, Dhillon et al. (2016) use the National Election Survey from 2004, which surveys voters at the parliamentary constituency level, to examine the correlation of standard economic indicators with night-lights in India. They find the correlation of night-lights with wealth to be about 0.6 , while that with income and education lies between 0.4 and 0.45 .20 Overall, these studies find a strong within country relationship between GDP levels and night-time lights intensity and growth rates (see Pinkovskiy and Sala-i-Martin 2016). Night-time lights data offer several advantages, most importantly that the pixels can easily be aggregated to the constituency level and that the availability of annual frequency allows for more detailed temporal analysis. Moreover, whether through increased electrification or higher incomes levels, it should arguably be related to local economic activity.

\footnotetext{
${ }^{17}$ Based on the Delimitation Order of 1976, the constituency boundaries remained fixed till 2008. As a result, there were 4,120 state assembly constituencies. According to the Delimitation Order of 2008, the number of Assembly constituencies are 4,033. Between the 2001 and 2011 Censuses, the number of districts increased from 593 to 640.

${ }^{18}$ Henderson et al. (2012) shows that night-time lights can also identify short run fluctuations, including the Asian Financial Crisis in Indonesia between 1997 and 1998 and the Rwandan Genocide between 1993 and 1994. Thus satellite night-time lights data are a useful proxy for economic activity at temporal and geographic scales for which traditional data sets are of poor quality or are unavailable (Henderson et al. 2012). Additionally, prior research shows that the Defense Meteorological Satellite Program's Operational Linescan System (DMSP-OLS) can reliably detect electrified villages in developing countries and that the night lights output is a useful proxy for electricity provision (Doll et al. 2006, Min et al. 2013, Baskaran et al. 2015). Recent papers have used night-time lights data to study growth of cities in sub-Saharan Africa (Storeygard 2014), production activity in blockaded Palestinian towns of the West Bank (Abrahams 2015, van der Weide et. al 2015), and urban form in China (Baum-Snow and Turner 2012) and India (Harari 2015).

${ }^{19}$ Michalopoulos and Papaioannou (2014) show that light density is correlated strongly with proxies of public goods including as access to electrification, the presence of a sewage system, access to piped water, and education and development. Min (2008) finds a strong association between access to electricity, public-goods provision and night light intensity for low income countries.

${ }^{20}$ Similar relationship holds at the district level in India (see Chaturvedi et al. 2011 and Bhandari and Roychowdhury 2011).
} 
The satellite data are collected by the National Aeronautics and Space Administration's (NASA) Defense Meteorological Satellite Program's Operational Linescan System (DMSP-OLS) via a set of military weather satellites that have been orbiting the earth since $1970{ }^{21}$ The result is a series of images covering the globe for each year from 1992 onwards (Elvidge et al. 1997, 2001). Images are scaled onto a geo-referenced 30 arc-second grid (approximately $1 \mathrm{~km}^{2}$ ). The key dependent variable is computed as the sum of all light values from all of the pixels within the boundaries of each state assembly constituencies as defined by the Election Commission of India. ${ }^{22}$ Thus, we aggregate nighttime lights output to the state level assembly constituency to estimate economic costs of electing criminally accused politicians.

In the night-time lights data, each pixel is encoded with a measure of its annual average brightness on a 6-bit scale from 0 to 63 . Thus, it is top-coded at 63 and censored at 0 (i.e. the brightest areas are not well measured and areas require some minimum level of light to be captured). Topcoding is a concern since we are unable to observe increases in lighting above 63 . However, this should not be systematically related to close elections of criminally accused candidates. That said, we subsequently replicate our analysis with and without the top coded constituencies to verify the robustness. Another potential issue is blooming, which occurs when light from a brightly lit area spills over into neighboring areas. While this is a concern around large cities, our sample is predominately rural. However, for rural areas a related concern is whether night-time lights capture rural activity. As we discussed above, night-time lights also allows dimmer lights to be captured in rural, electrified areas.

Lastly, the levels of light output are relative brightness values. Since there is no onboard radiance calibration on the satellite sensors, there is no way to convert the relative brightness values to an actual level of illumination. This complicates time series analysis because changes in observed brightness in different annual composites may be due to real changes in light output on the ground or due to technical factors related to gain levels or sensor properties. We follow Henderson et al. (2012) and Chen and Nordhaus (2011), and account for this limitation by including year fixed

\footnotetext{
${ }^{21}$ The satellites record high resolution images of the entire earth each night typically between 8:30 and 10:00 pm local time. The images, captured at an altitude of $830 \mathrm{~km}$ above the earth, record concentrations of outdoor lights, fires, and gas flares at a fine resolution of $0.56 \mathrm{~km}$ and a smoothed resolution of $2.7 \mathrm{~km}$. These images are used to produce annual composites during a calendar year, dropping images where lights are shrouded by cloud cover or overpowered by the aurora or solar glare, and removing ephemeral lights like fires, other temporary lighting phenomenon and noise.

${ }^{22}$ We use GIS data on administrative boundaries of states and assembly constituencies to enable the aggregation within each state assembly constituencies.
} 
effects in our estimating equation to control for contemporaneous shocks affecting all units in a year, including any factors that may affect the overall brightness detected by a sensor in any given year. Finally, we utilize the data available on stable night lights that drop light values from pixels with unstable light signatures over time.

Our key dependent variable is the yearly growth in night-time lights. This is the difference in the natural log of night-time lights intensity for the constituency between the periods $(t+1)$ and $(t)$. As discussed earlier, this has been widely accepted in the literature as a proxy for economic activity. Another advantage of specifying the dependent variable in this form is that it allows us to roughly calculate the impact on GDP using estimates from the literature on the elasticity of GDP growth to night-time lights growth. We also present results using two alternate dependent variables: the natural log of night-time lights, and the growth of night-time lights averaged over the entire election term. These additional dependent variables are likely to be less sensitive when comparing growth of night-time lights over time. We report the descriptive statistics of the key dependent variables in Table 1-A. The dependent variables are observed for each year of the election term, thus we observe about 4 observations for each included state level constituency.

Finally, we also use another outcome variable that is a proxy for public good provision at the constituency level: the length of roads built under the PMGSY program (in kms). PMGSY is a fully centrally sponsored rural roads construction program launched in 2000 that aims to provide all weather road connectivity in rural areas, and forms an integral part of the Government of India's poverty reduction strategy. This program has been described as "unprecedented in its scale and scope" (Aggarwal 2015), connecting over 116,000 habitations with roads and another 23,000 currently under construction as of January 2016. Under PMGSY, about 360,000 kms of rural roads are being constructed with a projected investment of approximately US $\$ 14$ billion for construction and US $\$ 9$ billion for "upgradation" of existing tracks. The administrative records of length of roads built under PMGSY are publicly available in the Online Management and Monitoring System (OMMS). We match roads data to the state assembly constituency level data to estimate the impact of electing criminally accused politicians on this measure of public good in Section $6{ }^{23}$

\footnotetext{
${ }^{23}$ The 2001 Census is the source for habitation-level data, which are collected by the PMGSY in order to determine the prioritization of roads. The PMGSY data are available at the census block level. Although there is no one-toone matching between census blocks and state assembly constituencies (for e.g., a block can span more than one constituency), we match a block to a specific constituency if at least 50 percent of the villages in the block fell in that constituency.
} 


\subsection{Election Results and Affidavit Data}

We use the Election Commission of India (ECI) Statistical Reports on General Elections to State Legislative Assemblies for election data. ${ }^{24}$ These reports provide important information related to elections, such as the name and code of the constituency, candidates and their vote shares, electorate size (number of registered voters), number who turned out to vote (number of voters), the candidate's gender and constituency type (whether reserved for SCs (STs) or non-reserved) 25 For criminal accusations, we rely on the data from sown affidavits that have been collected and digitalized by the Election Watch, in collaboration with the Association for Democratic Reforms (ADR) ${ }^{26}$ The ADR data provide information on the number of criminal cases against each candidate, the charges associated with each criminal case, a classification of each accusation as serious or not, the asset and liabilities disclosures of each candidate and each candidate's level of education.

We consider all state elections held between 2004 and 2008. While the light data are available from 1992 onwards, we are limited by the data on affidavits, which became mandatory only after the Supreme Court order in 2003. Further, ADR data are available only for elections held after 2004. As a result, we have a sample of 20 states out of a total of 28 covering approximately 90 percent of India's total electorate ${ }^{27}$ Also, the constituency boundaries changed in 2008 meaning constituencies before and after delimitation are not comparable ${ }^{28}$ Thus, between the Court order to file affidavits in 2003 and the redrawing of boundaries in 2008, we observe only 1 election per state. However, we utilize the night-lights data until 2012 for some states ${ }^{29}$ Table A-1 reports the information on the

\footnotetext{
${ }^{24}$ The reports are available at http://eci.nic.in/eci_main1/ElectionStatistics.aspx accessed in May 2014.

${ }^{25}$ According to the Indian Constitution, certain seats are reserved for Scheduled Castes (SCs) and Scheduled Tribes (STs), the two historically disadvantaged minority groups. While registered voters from all social groups can vote, only an SC (ST) candidate may contest election from the seats reserved for SC (ST).

${ }^{26}$ The ADR data is available for public use at www.myneta.info.

${ }^{27}$ The included states are Arunachal Pradesh, Assam, Bihar, Goa, Gujarat, Haryana, Himachal Pradesh, Jharkhand, Kerala, Maharashtra, Manipur, Meghalaya, Nagaland, Odisha, Punjab, Tamil Nadu, Tripura, Uttar Pradesh, Uttarakhand and West Bengal. The states excluded from our analysis are Andhra Pradesh, Chhattisgarh, Jammu and Kashmir, Karnataka, Madhya Pradesh, Mizoram, Rajasthan and Sikkim. Note that these states are excluded from the analysis based on the pre-determined timing of their elections. Consequently, there is no reason to believe that there are any systematic differences between included and excluded states (particularly with respect to the growth of night lights or criminally accused candidates).

${ }^{28}$ The boundaries for constituencies were fixed in 1976 until the Delimitation Act of 2002. This Act constituted a Delimitation Commission to redraw the constituency boundaries based on the 2001 census figures. Based on the delay in compiling the necessary data and in creating the new boundaries, the first election with redrawn boundaries was only held in Karnataka in 2008. Consequently, the period between 1976 and 2008 had fixed constituencies boundaries allowing for the comparison of satellite imagery across time. Once the new boundaries were implemented, it is not possible to make a comparison between the two periods.

${ }^{29}$ The affidavits are available starting with the first election held after the Supreme Court order in 2003. For example, the order was first effective in 2004 in Arunachal Pradesh and the first election after the boundaries changed
} 
number of assembly constituencies and information on year in which the elections were held in each state after the Supreme Court order from the ADR website.

Our main variable of interest is the criminal accusations ${ }^{30}$ A potential concern with accusations is that political rivals may file false cases to gain electoral advantages. Unfortunately, it is not possible to distinguish between "true" and "false" criminal accusations. Despite this limitation, these data have been widely used to measure criminal accusations (Aidt et al. 2015, Asher and Novosad 2014, Banerjee et al. 2014, Fisman et al. 2014). There is some evidence to suggest that false cases are not as frequent as might be believed. Looking at a sub-sample of states, Vaishnav (2011a) finds that accusations are unrelated to prior electoral performance (a proxy for popularity), incumbency, and the timing of elections. In addition, only cases filed 6 months prior to elections need to be reported, therefore it is less likely the criminal charges are electorally motivated.

In our baseline specification, we define a binary variable for whether or not a candidate is currently accused in any criminal case. Specifically, this variable takes a value of 1 if MLA faces any current criminal cases and 0 otherwise. Given the setup in a RD design, we only consider races in which, among the top-2 candidates, one is accused and the other is non-accused. This is because the RD design implicitly assumes that voters are faced with a choice between two types of candidates (accused and non-accused). In practice, the top-2 (or even all the candidates) might be of the same type. We therefore restrict the sample to constituencies in which the top-2 candidates represent each type (accused and non-accused). This restricts our sample from the full 2633 constituencies for which we have data to a smaller sample of 941 constituencies, which are observed annually during our sample period over two successive elections in each state, totaling over 3600 observations 31

While we are not the first study to use the data on criminal accusations, few studies, Vaishnav (2011a) being a notable exception, consider the type of charges. This is particularly important

was held in 2009. So for Arunachal Pradesh, our (post-treatment) sample period is from 2004-2009. However, for Uttar Pradesh the first election after the order, took place in 2007 and the first election after the changes in the boundaries was held in 2012. As a result, our sample period for Uttar Pradesh is from 2007-2012.

${ }^{30} \mathrm{It}$ is not possible to examine convictions since there are only a handful of cases in which criminal proceedings lead to a conviction. Ideally, we would be able to use earlier accusations and examine whether candidates are subsequently convicted. However, the data on accusations are only recent and the Indian judicial process frequently takes years or even decades to resolve cases. According to Sukhtankar and Viashnav (2015), of the 76 MPs serving in the 15th Lok Sabha (2009 national elections) who faced ongoing criminal action, the case had been pending for an average 7 years.

${ }^{31}$ Note that our results are robust to using the full sample. We choose this restricted sample since this is the implicit comparison in a RD design. According to Lehne et al. (2016) the median number of candidates per state assembly election is eight, however only the top- 2 candidates are competitive: the third placed candidates average $7 \%$ of the vote, the fourth placed candidates average $3 \%$, the fifth $1.6 \%$ and the rest less than $1 \%$. 
since not all charges are of the same severity or relevance in assessing a candidate's aptness for public office. We consider whether a specific charge associated with a criminal case is serious, and whether it is related to any financial wrongdoing. Since any definition of serious criminal charges is inherently arbitrary, we rely on the classification used by the ADR which is based on such factors as the maximum punishment under the law, their violent nature, and offenses under the Prevention of Corruption Act ${ }^{32}$ Since ADR does not classify charges into financial and non-financial categories, we define a charge as financial if the corresponding IPC refers to a crime resulting in a loss to the public exchequer ${ }^{33}$ Similar to the variable for any criminal case, we create binary variables for whether or not a candidate is accused of a serious or financial criminal charge.

Our baseline definition of criminal accusations is whether a candidate has any criminal case against him/her. We refine our definition of criminally accused further by considering candidates who face multiple criminal cases. Insofar as there is a cost to framing false cases against politicians, we might expect that a higher number of cases might be a more reliable indicator of a politician's true type. Additionally, this also provides a measure of the "intensity of the treatment". Accordingly, we should expect the treatment effects to become larger as the treatment intensity increases. We consider two thresholds: a candidate is criminally accused if he/she has 2 or more cases or if he/she has 5 or more cases.

Table 1-C reports descriptive statistics of the data on criminal accusations. Approximately 53percent of the winners in our sample report at least one criminal case, while 40-percent are facing at least one serious charge, and 19-percent at least one financial charge. Although some of the differences between the winners and the runners-up are statistically significant in the full sample in Table 1-B, these become insignificant when we look at the sample of close elections which is selected by the optimal bandwidth criterion. Table 1-B also reports the predetermined constituency and

\footnotetext{
${ }^{32} \mathrm{ADR}$ compiles detailed data on each candidate's criminal cases and the type of charges framed in each case. It reports the exact criminal charge(s) for each candidate as defined under the Indian Penal Code (IPC). The IPC is the main criminal code of India that covers all substantive aspects of criminal law. ADR defines serious criminal charges using eight criteria. They are: (1) Whether the maximum punishment for the offense committed is of five years or more, or; (2) Whether the offense is non-bailable, or; (3) Offenses pertaining to the electoral violation (IPC 171E or bribery), or; (4) Offense related to the loss to exchequer, or; (5) Offenses the nature of which are related to assault, murder, kidnap, rape, or; (6) Offenses that are mentioned in Representation of the People Act, or; (7) Offenses under Prevention of Corruption Act, or; (8) Offenses related to the Crimes against women. The following is a link to an online Appendix on ADR criteria for coding serious crimes/http://adrindia.org/content/ criteria-categorization-serious-criminal-cases.

${ }^{33}$ This classification is based on consultations with several high level Indian Police Service officers and we classify the following IPCs as financial crimes: 171B, 171E, 230-262, 272, 273, 274, 275, 276, 378-420, and 466-489D.
} 
candidate characteristics for the previous year, thus only includes 1 data per included constituency. Further, Figure A-7 depicts the distribution of criminally accused MLAs across Indian States.

\subsection{Validity of the RD Design}

There are two standard tests to show the validity of the RD design (Imbens and Lemieux 2008). The first is the McCrary (2008) density test for a discontinuity at the cutoff in the density of the forcing variable. In our context, this tests for whether criminally accused candidates disproportionately win close elections. For instance, criminally accused politicians might be able to manipulate elections and therefore be more likely to win close elections, thereby violating the identifying assumption that the treatment is randomly assigned. If this were the case, we would find a larger frequency of criminally accused candidates compared to non-accused candidates in the neighborhood of the cutoff. This would imply that the density of the margin of victory, the forcing variable, would show a discontinuity at the cutoff. Panels (a)-(b) of Figure 1 shows that the density of the victory margin above and below the cutoff is not statistically significant.

The second test of the validity of the RD design is whether the observed characteristics of candidates and constituencies are continuous around the cutoff. That is, while the characteristics for criminally accused and non-accused candidates may be different over the entire sample, with the exception of the treatment, no other variable should be discontinuous around the cutoff. For instance, recent papers (Caughey and Sekhon 2011, Grimmer et al. 2011) have shown that in the context of U.S. elections, the incumbent party tends to have systematically greater chances of winning even when elections are close. However, Eggers et al. (2014) use data on 40,000 closely contested races in different electoral settings, including India, and do not find any systematic evidence of sorting or imbalance around the electoral thresholds.

We formally check for continuity of various constituency characteristics in Figure 2 and candidate characteristics in Figure 3. The variable on the y-axis is net of state and year fixed effects. The dots in the scatter plot depict the averages over each successive $0.5 \%$ interval of the margin of victory. The curves are local linear regressions fit separately for positive and negative margins of victory using

a triangular kernel and the optimal bandwidth calculator suggested by Imbens and Kalayanaraman (2012). The confidence intervals are the $95 \%$ confidence intervals plotted using standard errors that 
are clustered at the constituency level.

In Panels (a)-(g) of Figure 2, we compare accused winners to non-accused winners on growth of night lights in the prior years (t-1 and t-2) and on several other constituency characteristics: the electorate size, the number of voters, whether a constituency was aligned with the ruling party in the state, in the previous election, and whether a constituency is reserved for Scheduled Caste (SC) or Scheduled Tribes (ST). Similarly, in Panels (a)-(c) of Figure 3, we perform the continuity checks for candidate characteristics: MLA's incumbency status and gender, in the previous election. These results indicate that there are no statistically significant differences in the observed covariates around the cutoff. Therefore, the results from the McCrary test and the continuity of covariates strongly suggest that the assumptions underlying the RD design are valid in this setting and that the outcome of a close election is as good as random.

\section{Criminally Accused Politicians and Economic Activity}

\subsection{Main Results}

We present the main results with a graphical illustration of the RD effect of electing criminally accused candidates in Figure 4 which plots the yearly growth of night-time lights against the margin of victory for the criminally accused candidates ${ }^{34}$ The yearly growth of night-time lights is the residual from the regression of yearly growth of night-time lights on state and year dummies. The scatter plot shows the local averages of the residuals in each successive interval of 0.5 percent of margin of victory. The solid curves are plotted non-parametrically using a local linear regression with a triangular kernel and the optimal bandwidth criterion proposed by Imbens and Kalyanaraman (2012). Positive margins of victory indicate a constituency in which a criminally accused candidate won against a non-accused candidate (the runner-up), while a negative margin shows that she/he was the runner-up and that the winner was not criminally accused. The RD figure shows a sharp difference in the average yearly growth of night lights at the cutoff $(M A R G I N=0)$. The vertical difference between the red and blue lines reflects the estimated causal effect of electing a criminally accused candidate on the yearly growth of night-time lights. In particular, at the cutoff, there is a

\footnotetext{
${ }^{34}$ The sample consists of elections in which, among the top- 2 candidates, one is accused and the other is non-accused (see Section 4.2 for detailed discussion).
} 
statistically significant and negative effect of electing a criminally accused candidate.

Table 2 reports the size of the estimated RD effects. In column (1) we use a local linear regression with the optimal bandwidth $(h)$ criterion proposed by Imbens and Kalyanaraman (IK). This is our main specification and is analogous to Figure 4. We find a statistically significant negative effect of electing criminally accused candidates: the annual growth of night-time lights is approximately 22 percentage points lower in constituencies that barely elect a criminally accused candidate as compared to those constituencies that barely elected a candidate without accusations 55 For robustness, we also present these results using alternate bandwidths in columns (2)-(4). In column (2), we use a bandwidth calculated using the Calonico, Cattaneo and Titiunik (CCT) (2014) algorithm, while in columns (3)-(4) we halve and double the IK bandwidth, respectively. The results in column (2) are quantitatively identical to those in column (1). Halving the bandwidth in column (3) results in a slightly larger estimate, while doubling the bandwidth in column (4) leads to a smaller estimate. Overall, the results remain statistically significant and similar in magnitude.

As discussed in sub-section 4.1, we use the intensity of night-time lights as a proxy for economic activity (see Pinkovskiy and Sala-i-Martin 2016 for an overview on the link between night-time lights data and GDP). It is, however, unclear what is driving the changes in night-time lights. For example, the growth in night-time lights could represent changes in the supply of electricity. Alternately, it could be attributable to changes in demand, or some combination of the two. Irrespective of whether these changes are supply or demand-side driven, economic activity and the intensity of night-time lights should be correlated (although certainly not one-to-one). While we currently interpret these results in terms of night-time lights intensity, we compute the corresponding decline in GDP using existing estimates of the elasticity of growth of night lights to the growth of GDP in Section 7.

\subsection{Types and the Number of Charges}

In this subsection we begin by examining whether the costs of electing accused politicians vary based on the underlying charges. If the economic costs associated with electing criminal politicians are attributable to accused politicians, we would expect that both the type of charge and the number of underlying cases would matter. As noted in sub-section 4.2, we define the types of charges, first,

\footnotetext{
${ }^{35}$ In Table A-2 we estimate Table 2 with year fixed effects (in Panel A) and with state-year fixed effects (in Panel $\mathrm{B})$ and find the RD estimates to be identical.
} 
by their seriousness, and second, by whether the charges are related to any loss to public exchequer (financial crimes).

We report the results by the type of charges in Table 3. In columns (1)-(4) of Panel A, we estimate the RD effect of electing candidates accused of financial charges on the yearly growth of night-time lights. In particular, we compare constituencies with a winner who is accused of at least 1 financial charge (and a loser who is not accused) to constituencies with a non-accused winner (and a loser who has at least 1 financial charge). Similarly, in columns (5)-(8), we examine the effect of electing candidates accused of only non-financial crimes where we compare constituencies with a winner who is accused of at least 1 crime but has no financial charge (and the runner up is not accused) to constituencies with a non-accused winner (and a runner up with at least 1 accusation but no financial accusation). We perform a similar analysis with serious charges in Panel B. We find consistent results: the type of charges matters. The coefficients for both financial and serious crimes are consistently significant and larger in magnitude (in absolute terms) than those estimated for any charge in column (1) of Table 2 . In contrast, non-financial and non-serious charges are consistently statistically insignificant.

In Table 4, we examine the effect of the number of criminal cases. A larger number of cases can be viewed as a "higher intensity treatment" and, insofar as there are costs to manufacturing and filing false charges, may be more likely to represent "true" accusations. In columns (1)-(4) we present the results of the impact of electing a candidate with two or more charges, while columns (5)-(8) present the results for candidates accused of five or more charges. Similar to the results with financial and serious charges, the number of criminal cases has a clear negative effect. The estimated coefficients are consistently negative and statistically significant and greater than the effect for any charge [column (1) in Table 2] ${ }^{36}$ Taken together, the results from Tables 3 and 4 demonstrate that the characteristics of the candidate, specifically the candidate's accusation record, underlie the earlier results and that the costs increase with the severity of the charge.

\footnotetext{
${ }^{36}$ We estimate similar models using the alternate thresholds of 2 and more financial (serious) charges, and 5 or more financial (serious) charges. The results are qualitatively similar to those in Table 4. The table is available upon request.
} 


\subsection{Timing of the Negative Effects}

We next examine whether the effect of electing accused politicians varies across the years of an accused politician's term. That is, is the negative effect instantaneous (e.g. appear in the first year of the term) and then remains constant throughout the term or rather does it accumulate over time?

In Table 5, we estimate the effect of elected an accused candidate separately for each year of the term. We also present the graphical illustration of the RD effect in Figure 5. The results show that the negative effect does not appear instantaneously; there are no effects in the years 1 or 2 . In contrast, the estimated coefficients become statistically significant in years 3 and 4 , with both the magnitude and significance of the estimated coefficient increasing over time.

We interpret these findings to mean that the election of criminally accused politicians does not instantaneously result in lower economic activity and that the economic costs show up after a lag. For politicians to engage in corrupt behavior, they require collaboration with local bureaucrats (Iyer and Mani 2012). Consequently, a certain amount of time is necessary for corrupt politicians and bureaucrats to form a nexus and to engage in corrupt activity. For example, the effect of neglected public infrastructure, such as roads etc., may take some time to slow down economic activity.

\subsection{Heterogeneous Impact by State Characteristics}

We now examine whether the effect of electing criminally accused politicians varies with state characteristics. First, we consider the so-called "BIMAROU" states of Bihar, Jharkhand, Odisha, Uttar Pradesh, and Uttarakhand (The acronym BIMAROU is formed using the first letters of the word 'sick': in Hindi). These states are widely considered to be lagging behind in terms of economic development and have been singled out for being corrupt and generally dysfunctional. Second, we consider the set of states that the Ministry of Finance classifies as being "Least Developed" and "Relatively Developed" ${ }^{37}$ Finally, using measures of corruption created by Transparency International India's (TII), drawn from the India Corruption Study of 2005, we classify states into "High-Corruption" and "Low-Corruption" states 38

\footnotetext{
${ }^{37}$ The Ministry of Finance classifies the following states as being "Least Developed": Arunachal Pradesh, Assam, Bihar, Jharkhand, Odisha and Uttar Pradesh and "Relatively Developed": Goa, Haryana, Kerala, Maharashtra, Punjab, Tamil Nadu, and Uttarakhand.

${ }^{38}$ TII classifies the following states as being "High Corruption": Tamil Nadu, Haryana, Jharkhand, Assam, and Bihar and "Low-Corruption": Kerala, Himachal Pradesh, Gujarat, Maharashtra, Punjab, West Bengal, Odisha, and
} 
We present the results in Table 6. The RD estimate for BIMAROU states are reported in Panel (A), while Panel (B) reports the estimate for Least Developed states, and finally Panel (C) reports the estimate for High-Corruption states. These effects are negative and statistically significant. The size of the coefficients for BIMAROU and Least Developed states are roughly one and a half times larger than our main result [Table 2, column (1)] and slightly more than double for High-Corruption states [The coefficient is -21.74 for our baseline result (all states), -45.76 for BIMAROU states, -49.46 for Least Developed states, and -51.29 for High-Corruption states]. However, the results are statistically insignificant for Non-BIMAROU, Relatively Developed and Low Corruption states as shown in Table A-3.

Since there is substantial overlap between the states in the BIMAROU, Least Developed and High Corruption classifications, it is difficult to isolate one particular factor. Rather, we see that the effects of electing accused politicians are largely confined to certain states. One common feature of these states is the relatively weaker institutions whether judicial, police or political. Anecdotal evidence suggests that in states with stronger institutions, the actions of criminal politicians are more constrained. In contrast, those states with lower quality institutions have reputations of lawless behavior and general impunity for politicians and bureaucrats. Thus, a criminally accused politician may be more able to compromise governance where institutions are weaker or less developed.

\section{Criminally Accused Politicians and Public Good}

Our main results use night-time lights as a measure of economic activity. Using data from the PMGSY program, we examine an alternate measure of economic development and a proxy for public good provision: the length of roads built annually under PMGSY (in kms).

We present the graphical illustration of the RD effect (and the balance test) of electing criminally accused candidates on the length of roads built annually in Figure 6 and the results from local linear regression by state characteristics and the types of accusation in Tables 7, 8 and 9 . We report the results for all states in Panel A, BIMAROU states in Panel B, Least Developed states in Panel C, and High Corruption states in Panel D. We find that the length of roads constructed is lower in constituencies represented by criminally accused candidates (Panel A in Figure 6 and Table 7) as 
compared to constituencies that elected non-accused candidates. Similar to the night-time lights results (Table 6, Panel A and B), we find the negative impact varies by 'BIMAROU' and 'Least Developed' states, although the estimated coefficient no longer varies by the types of accusation. Overall, it is reassuring to find similar results using a completely different measure of economic development.

Surprisingly, we do not find negative impact of electing criminally accused politicians on roads construction for the high corruption states; this may be due to the smaller number of road projects approved and constructed in some of the high corruption states ${ }^{39}$ In addition, these states are less dependent than the BIMAROU or Least Developed states on federal transfer of funds. Lastly, we cannot rule out the fact that the nature of corruption might differ in high corruption states; for example, criminal politicians could be corrupt in ways that are harder to detect and not necessarily through the roads construction program.

Road construction in India is widely believed to be plagued with rampant corruption and frequently involves manipulation of the tenders and the process of procurement, often leading to lower quality and unfinished road projects (WSJ 2012) 40 :41 By matching contractors' and political candidates' last names in the PMGSY program, Lehne et al. (2016) finds a 63-percent increase in the share of roads allocated to contractors who share their last name when the politician gets elected. In addition, they show that the preferential allocation also increases the likelihood of missing roads using the 2011 census data. They advance two reasons to explain why a road would be listed as missing, both of which are indicative of corruption. Firstly, roads may be listed as completed without ever being built. Secondly, roads could be built with sub-standard materials leading to their complete or partial deterioration by the time of the 2011 census.

These results complement our findings with the night-time lights and are consistent with the view that accused politicians are detrimental to economic development and public good delivery.

\footnotetext{
${ }^{39}$ States that have recorded the highest road construction are the BIMAROU and Least Developed states, for e.g. Madhya Pradesh $(63,548 \mathrm{~km})$, followed by Rajasthan $(58,462 \mathrm{~km})$, Uttar Pradesh $(45,905 \mathrm{~km})$, Bihar $(35,510 \mathrm{~km})$ and Odisha $(35,019 \mathrm{~km})$.

40 http://blogs.wsj.com/indiarealtime/2012/05/04/road-building-still-tarred-with-corruption/.

${ }^{41}$ A senior official reported that "road mafias" of contractors, engineers, the local police, civil servants, "and last but not least local politicians", conspire to keep prices on road contracts above market rates (Singh 2005).
} 


\section{Rough Calculation of the Effect on GDP}

In this section, we calculate a rough estimate of the impact of criminally accused politicians in terms of GDP loss. So far, due to the absence of local economic indicators, we use changes in the intensity of night-time lights as a proxy for economic activity; however, it is possible to estimate the impact in terms of GDP by using existing estimates of the elasticity of GDP with respect to night-time lights. These elasticities have been calculated in settings where data exist for both the intensity of night-time lights and local economic activity. In particular, we focus on Henderson et al. (2012) estimate for a global sample of low and medium income countries, 0.3, and Bickenbach et al.'s (2013) India-specific district-level estimate of elasticity of 0.107. Since there are no reliable and systematic figures for growth at the constituency level, the latter represents the most disaggregated estimate of the elasticity for India. These two elasticities allows us to calculate a rough upper and lower-bound estimate of the effect on growth rate of GDP.

We present the "back of the envelop calculations" of GDP loss in Table 10. For the ease of calculation, we report the RD estimates for the three types of accusations in Panel A (i.e. estimates from column (1) of Table 2, and column (1) from Panel A and B of Table 3). In Panel B, we calculate the impact of electing a criminally accused candidate on the growth rate of GDP in column (1), for candidates accused of at least one financial charge in column (2), and finally for candidates accused of at least one serious charge in column (3). These estimates are calculated by multiplying the coefficients in Panel A with the relevant elasticities from the literature (i.e. the upper bound uses the elasticity of 0.3 , while the lower-bound uses the elasticity of 0.107 ). Depending on the type of criminal accusation, we find estimates ranging from 2.3-6.5 percentage point lower GDP growth per year for our baseline estimates [column (1) in Panel A].

Lastly, in Panel C, we calculate what would the GDP loss look like under these different scenarios based on the estimates from Panel B. Using a conservative estimate of 6-percent GDP growth as a measure of average yearly constituency growth, this would imply that, on average, electing a criminally accused candidate would result in a 5.61 to 5.86-percent GDP growth per year (as compared to the 6-percent otherwise) ${ }^{42}{ }^{43}$ These calculations are conservative since they are estimates of the

\footnotetext{
${ }^{42}$ During this period, India experienced high growth rates ranging from 7.9 percent in 2003 to 9.8 percent in 2007.

${ }^{43}$ These growth rates are based on the estimated effects on Panel B. For instance, the upper bound estimate in column (1) is -6.5 percent. Consequently, the constituency would only experience 93.5 percent of the normal growth
} 
yearly cost, such losses are likely to compound over the full 5 year term.

These rough estimates of the cost in terms of GDP growth raise parallel questions in terms of the foregone poverty reduction and the effects on distribution. While the data do not exist to verify this, it is important to highlight that these are not just aggregate constituency-level costs; they are likely commensurate micro-level costs.

\section{Robustness}

In this section, we perform further robustness checks using alternate functional forms, and alternate definitions of the dependent variable. We also re-estimate our main result after controlling for covariates in the RD regression (similar to Meyersson 2014), and finally examine the impact of top coding on our results.

\subsection{Sensitivity Analysis of RD Specification}

While earlier researchers emphasized the analysis of different bandwidths (Imbens and Lemieux 2008), recent studies broaden the focus to include alternate control functions (Dell 2010, Lee and Lemieux 2009, Meyersson 2014). We address this in Table A-4 which reports the RD effects for linear, quadratic, cubic, and quartic functions using the IK (h), CCT, h/2, and $2 \mathrm{~h}$ bandwidth choices ${ }^{44}$ Variations in the polynomial order in the control function are ordered by row and bandwidth choices by column in this table.

By and large, we find that the RD estimates are negative and statistically significant and qualitatively similar to the effect estimated in Table 2. Statistical significance, however, is lost with larger bandwidth and/or polynomial order of the control function.

\subsection{Alternate Dependent Variables}

Since night-time lights and their distribution can be measured in several ways, we explore two alternate definitions of the dependent variable: the intensity of night lights in levels $[$ Log $($ Night Lights)]

which is 5.61 GDP growth per year.

${ }^{44}$ In results we do not present here, we also re-calculate the RD estimates using alternate bandwidth choices, specifically $0.9 h, 1.3 h, 1.7 h, 2.1 h$, where $h(I K)=6.35$. We further repeat the same exercise for four additional bandwidths (i.e. 2.5, 5.0, 7.5, and 10.0) and find similar results. Both tables are available upon request. 
and the growth of night-time lights averaged over the election term of the candidate (Average Growth over the Election Term). We present the estimates from RD effect for the two dependent variables in Table A-5 45

While we focus on the yearly growth of night-time lights (for better comparison across constituencies), both growth rates and levels are used when researchers talk about growth. Moreover, large percentage changes due to a small initial level can mask very small absolute changes. We therefore estimate the local linear RD regression using the IK bandwidth for night-time lights in levels and present the result in column (1). For our second measure, we consider the growth of night lights averaged over the election term of the candidate to address the potential effect of year to year volatility. We present this estimate in column (3).

Results from Table A-5, columns (1)-(2) suggest that the point estimates remain statistically significant and negative using the alternate definitions of the dependent variable.

\subsection{Controlling for Covariates}

In an $\mathrm{RD}$ framework, it is not necessary to control for various pre-determined covariates as the treatment is independent of these covariates at the cutoff. However, it is possible to directly control for the covariates and estimate the local linear RD regression. We present the $\mathrm{RD}$ results in Table A-6, where we do not control for baseline value of log night-lights in the year before election in Panel A and with the baseline value of log night-lights as a control in Panel B.

We present the RD regression result with only year fixed effects in column (1), with state and year fixed effects in column (2) [similar to Table 2, column (1)], and finally in addition to state and year fixed effects we add constituency characteristics (i.e. growth of night lights in t-1, growth of night lights in t-2, electorate size, number of voters, whether a constituency was aligned with the ruling party in the state, in the previous election, and whether a constituency is reserved for Scheduled Caste (SC) or Scheduled Tribes (ST)) and candidate characteristics (for e.g. MLA's incumbency status and gender, in the previous election) in column (2) .

Overall, our results remain similar to our main findings in Table 2. This provides further reassurance about the validity of the RD design in our context.

\footnotetext{
${ }^{45}$ The graphical illustration of the RD effect, and the validity of the balance test are available upon request.
} 


\subsection{Top Coding}

As previously noted, the night-time lights data are censored at 63 . While this is not an issue in less developed areas, this could be an issue in the wealthiest and most populated areas where we cannot observe any changes above an intensity of 63 . Although this is unlikely to be systematically correlated with the accusation status of elected candidates, we directly address this in Table A-7. In our RD sample, there are 63 fully lit constituencies. In Panel A, we drop any observations where the constituency-year pixel average is 63. In Panel B, we drop any constituency in which the average pixel intensity for any year is 63 . In both cases, the results are both qualitatively and quantitatively similar to our main results.

\section{Conclusions}

In this paper, we estimate the aggregate economic costs of electing criminally accused politicians at the constituency level using data on the intensity of night-time lights and the sworn affidavits of candidates on their criminal background. We find several important results. We find a large negative and causal impact as the yearly growth of the intensity of night lights is roughly 22-percentage point lower for constituencies that barely elect a criminally accused candidate as compared with those that do not. The estimated effect is not just statistically significant but it is also economically meaningful; this effect translates into roughly a 2.3-percentage point lower GDP growth per year [Column (1) from Panel B of Table 10]. While we only have aggregate constituency level outcomes, this forgone growth must also impact poverty reduction and other micro-level development outcomes.

Using data on the specific charges elected representative (e.g. serious or financial criminal charge vs. any criminal charge) we find large variation in the impact of electing accused politicians on the intensity of night-time lights. In contrast, the election of candidates with only non-serious or nonfinancial charges has no impact on the subsequent growth. Additionally, this effect increases with the number of underlying criminal cases, which may serve as an indicator of 'intensity of treatment'. This variation not only highlights the importance of the precise accusations but also more reliably captures the potential criminality of politicians. This possibility is further underlined by the gradual accumulation of the costs over time. 
We further examine how the impact of electing criminally accused candidates varies across state characteristics. We find that the costs are more pronounced in states with high corruption levels, lower levels of development and those which plausibly have weaker institutions ('BIMAROU' states). This suggests that the local context may mitigate the detrimental effect of electing lower quality politicians, such as accused politicians. While we cannot identify the precise channels, we believe that institutions can play an important role in constraining the actions of elected politicians. Additionally, in the spirit of Kremer's 'O-Ring' theory (1993), local growth might depend on several complementary pieces including effective leadership. In certain contexts, such as less developed areas, there is no redundancy in leadership making the effects of inferior politicians more detrimental.

Finally, using data on roads construction - a commonly used measure of public goods provision in developing countries - we find a large negative impact of criminally accused on the length of roads built under PMGSY. This negative effect varies by state characteristics and is largely driven by 'BIMAROU' and 'Least Developed' states.

We interpret our key dependent variable as a measure of economic activity, but it may also proxy for access to electricity. Taken together, roads construction and access to electricity are arguably some of the most important public goods in India, thus the negative impact we estimate is likely to have important welfare consequences. Consequently, the election of accused politicians and, more generally, of lower quality politicians may have adverse effects along a variety of dimensions.

More broadly, our results are consistent with the literature on patronage democracies. One manifestation of a patronage democracy is the election of politicians who are able and willing to provide targeted benefits (Burgess et al. 2015). These benefits could be targeted based on caste as in India (Chandra 2004), class, or ethnicity in other contexts. Therefore, instead of focusing on the overall outcomes (such as the delivery of public goods), voters focus on whether politicians can deliver targeted transfers to their specific group or caste. Not only are voters perhaps more likely to overlook accusations but these accusations might serve as a signal of the politician's willingness to use the office to reward fellow-group members (Chauchard 2014, Wade 1985). If true, our results suggest three consequences. First, this can result in the election of criminally accused candidates, and therefore potentially explain the ever increasing number of accused politicians who are elected in India. Second, the election of lower quality candidates in patronage democracies leads to lower 
aggregate growth. Third, these effects, however, are mediated by the local context (especially the institutional and legal context). In the more developed, and less corrupt states in our sample, the effects of the accused politicians were lower, perhaps due to the strength of institutions.

Although we study a particular context, lower quality politicians are believed to be pervasive in many developing countries. While the underlying cause is often context-specific and may range from caste-politics to tribal and ethnic voting, we believe that our analysis is suggestive for other contexts. 


\section{References}

Abrahams, Alexei. 2015. "Hard Traveling: Redistributive Effects of Commuting Costs in the Second Palestinian Uprising." Working Paper.

Aggarwal, Shilpa. 2015. "Do Rural Roads Create Pathways out of Poverty? Evidence from India." Working Paper.

Aidt, Toke, Miriam A. Golden and Devesh Tiwari. 2012. "Criminality in the Indian National Legislature." Working Paper.

Akhmedov, Akhmed and Ekaterina Zhuravskaya. 2004. "Opportunistic Political Cycles: Test in a Young Democracy Setting." The Quarterly Journal of Economics, 119 (4): 1301-38.

Alcantara, Manuel. 2008. "The Political Competence of Representatives in Latin America: An Analysis of Eleven National Cases." Annual Meeting of the American Political Science Association 2008.

Asher, Sam and Paul Novosad. 2014. "Dirty Politics: Natural Resource Wealth and Politics in India." Working Paper.

Asher, Sam and Paul Novosad. 2015. "Politics and Local Economic Growth: Evidence from India." Working Paper.

Association for Democratic Reform. 2012a. "Analysis of Candidates Contesting in Uttar Pradesh Assembly Elections 2012." Press Release on February 24th, 2012.

Association for Democratic Reform. 2012b. "Analysis of Criminal, Financial and other details of Newly Elected MLAs of the Uttar Pradesh Assembly Elections 2012." Press Release on March 11th, 2012.

Banerjee, Abhijit V., Selvan Kumar, Rohini Pande and Felix Su. 2011. "Do Informed Voters Make Better Choices? Experimental Evidence from Urban India." Working Paper.

Banerjee, Abhijit V., Donald Green, Jeffrey McManus and Rohini Pande. 2014. "Are Poor Voters Indifferent to Whether Elected Leaders are Criminal or Corrupt? A Vignette Experiment in Rural India." Working Paper. 
Banerjee, Abhijit V. and Rohini Pande. 2007. "Parochial Politics: Ethnic Preferences and Politician Corruption." Working Paper.

Bardhan, Pranab and Dilip Mookherjee. 2012. "Political Clientelism and Capture: Theory and Evidence from West Bengal." Working Paper.

Baskaran, Thushyanthan, Brian Min and Yogesh Uppal. 2015. "Election Cycles and Electricity Provision: Evidence from a Quasi-Experiment with Indian Special Elections." Journal of Public Economics, 126: 64-73.

Baum-Snow, Nathaniel and Turner, Matthew. 2012. Transportation and the Decentralization of Chinese Cities. Working paper.

Besley, Timothy, Rohini Pande and Vijayendra Rao. 2005. "Politician Selection and Quality of Government: Evidence from South India." Economic Growth Center Discussion Paper Series. Center Paper no. 921.

Bhalotra, Sonia and Irma Clots-Figueras. 2014. "Health and the Political Agency of Women." American Economic Journal: Economic Policy, 6 (2): 164-197.

Bhalotra, Sonia, Irma Clots-Figueras and Lakshmi Iyer. 2013. "Path-Breakers: How Does Women's Political Participation Respond to Electoral Success?." IZA Discussion Paper No. 7771.

Bhandari, Laveesh and Koel Roychowdhury. 2011. "Night Lights and Economic Activity in India: A Study using DMSP-OLS Night Time Images." Proceedings of the Asia-Pacific Advanced Network, 32, pp: 218-236.

Bhavnani, Rikhil. 2012. "Using Asset Disclosures to Study Politicians' Rents: An Application to India." Paper presented at World Bank Annual Bank Conference on Development Economics, Washington, DC, May 7-8.

Bickenbach, Frank, Eckhardt Bode, Mareike Lange and Peter Nunnenkamp. 2013. "Night Lights and Regional GDP." Kiel Working Paper No. 1888.

Bleakley, Hoyt and Jeffrey Lin. 2012. "Portage and Path Dependence." The Quarterly Journal of Economics, 12\%: 587-644. 
Broockman, David E. 2014. "Do Female Politicians Empower Women To Vote or Run for Office? A Regression Discontinuity Approach.” Electoral Studies, (34): 1-15.

Burgess, Robin, Remi Jedwab, Edward Miguel, Ameet Morjaria and Gerard Padro i Miquel. 2015 "The Value of Democracy: Evidence from Road Building in Kenya." American Economic Review, 105 (6): $1817-51$.

Bussell, Jennifer. 2012. "Corruption and Reform in India: Public Services in the Digital Age." New York: Cambridge University Press.

Callen, Michael, Saad Gulzar, Ali Hasanain, Yasir Khan and Arman Rezaee. 2015. "Personalities and Public Sector Performance: Evidence from a Health Experiment in Pakistan." NBER Working Paper No. 21180.

Calonico, S., M. D. Cattaneo, and, R. Titiunik. 2014. "Robust Nonparametric Confidence Intervals for Regression-Discontinuity Designs." Econometrica, 82 (6): 2295-2326.

Caughey, Devin and Jasjeet Sekhon. 2011. "Elections and the Regression-Discontinuity Design: Lessons from Close U.S. House Races, 1942-2008." Political Analysis, 19 (4): 385-408.

Chandra, Kanchan. 2004. "Why Ethnic Parties Succeed." Cambridge University Press, Cambridge.

Chaturvedi, Mayuri, Tilottama Ghosh and Laveesh Bhandari. 2011."Assessing Income Distribution at the District Level for India using Nighttime Satellite Imagery." Proceedings of the AsiaPacific Advanced Network, 32: pp. 192-217.

Chauchard, Simon. 2014. "Is 'Ethnic Politics' Responsible for 'Criminal Politics'? A VignetteExperiment in North India." Working Paper.

Chemin, Matthieu. 2012. "Welfare Effects of Criminal Politicians: A Discontinuity-Based Approach." The Journal of Law 8 Economics, 55 (3): 667-690.

Chen, Xi and William D. Nordhaus. 2011. "Using Luminosity Data as a Proxy for Economic Statistics." Proceedings of the National Academy of Sciences, 108 (21): 8589-8594.

Chopra, Vir K. 1996. "Marginal Players in Marginal Assemblies: The Indian MLA." Hyderabad: Orient Longman. 
Clots-Figueras, Irma. 2011. "Women in Politics: Evidence from the Indian States." Journal of Public Economics, 95: 664-690.

Clots-Figuerasa, Irma. 2012. "Are Female Leaders Good for Education?." American Economic Journal: Applied Economics, 4 (1): 212-244.

Cole, Shawn. 2009. "Fixing Market Failures or Fixing Elections? Agricultural Credit in India." American Economic Journal: Applied Economics, 1 (1): 219-250.

De Paola, Maria and Vincenzo Scoppa. 2010. "Political Competition and Politician Quality: Evidence from Italian Municipalities." Public Choice, 148: 547-559.

Dell, Melissa. 2010. "The Persistent Effects of Peru's Mining Mita." Econometrica, 78 (6): 18631903.

Dhillon, Amrita, Pramila Krishnan, Manasa Patnam and Carlo Perroni. 2016. "Electoral Accountability and the Ntural Resource Curse: Theory and Evidence from India." Cambridge Working Paper Economics: 1639.

Dinc, I. Serdar. 2005. "Politicians and Banks: Political Influences on Government-Owned Banks in Emerging Markets." Journal of Financial Economics, 77 (2): 453-479.

Doll C.N.H., Muller J.-P., Morley J.G. 2006. "Mapping Regional Economic Activity from Nighttime Light Satellite Imagery." Ecological Economics, 5\%: 75-92.

Eggers, Andrew C., Olle Folke, Anthony Fowler, Jens Hainmueller, Andrew B. Hall and James M. Snyder, J 2014. "On The Validity Of The Regression Discontinuity Design For Estimating Electoral Effects: New Evidence From Over 40,000 Close Races." American Journal of Political Science, 00 (00): 1-16.

Elvidge, Christopher D., Kimberly E. Baugh, Eric A. Kihn, Herbert W. Kroehl and Ethan R. Davis. 1997. "Mapping City Lights with Nighttime Data from the DMSP Operational Linescan System." Photogrammetric Engineering and Remote Sensing, 63 (6): 727-734.

Elvidge, Christopher D. et al. 2001. "Night-time Lights of the World: 1994-1995." ISPRS Journal of Photogrammetry and Remote Sensing, 56 (2): 81-99. 
Flyvbjerg, B. M. Holm and S. Buhl. 2003. "How Common and How Large are Cost Overruns in Transport Infrastructure Projects?" Transport Reviews, 23, (1): 71-88.

Ferraz, Claudio. 2007. "Electoral Politics and Bureaucratic Discretion: Evidence from Environmental Licenses and Local Elections in Brazil." Working Paper.

Fisman, Raymond. 2001. "Estimating the Value of Political Connections." The American Economic Review, 91 (4): 1095-1102.

Fisman, Raymond, Florian Schulz and Vikrant Vig. 2014. "Private Returns to Public Office." Journal of Political Economy, 122, (4): 806-862.

Gelman, Andrew, and Guido, Imbens. 2014. "Why High-order Polynomials Should not be Used in Regression Discontinuity Designs.” NBER Working Paper No. 20405.

Grimmer, Justin, Eitan Hersh, Brian Feinstein and Dan Carpenter. 2011. "Are Close Elections Random?" Mimeograph. Harvard School of Government.

Hahn, J., Todd, P., and Van Der Klaauw, W. 2001. "Identification and Estimation of Treatment Effects with a Regression Discontinuity Design." Econometrica, 69: 201-209.

Harari, Mariaflavia. 2015. "Cities in Bad Shape: Urban Geometry in India." Working Paper.

Henderson, J. Vernon, Adam Storeygard and David N. Weil. 2012. "Measuring Economic Growth from Outer Space." American Economic Review, 102 (2): 994-1028.

Hodler, Roland and Paul A, Raschkyl. 2014. "Regional Favoritism." Quarterly Journal of Economics, 124 (2): 995-1033.

Imbens, Guido W. and Thomas Lemieux. 2008. "Regression Discontinuity Designs: A Guide to Practice." Journal of Econometrics, 142 (2): 615-635.

Imbens, Guido and Karthik Kalyanaraman. 2012. "Optimal Bandwidth Choice for the Regression Discontinuity Estimator." The Review Of Economic Studies, 79 (3): 933-959.

Iyer, Lakshmi and Anandi Mani. 2012. "Traveling Agents: Political Change and Bureaucratic Turnover in India." The Review of Economics and Statistics, 94 (3): 723-739. 
Jaffrelot, Christophe and Gilles Verniers. 2014. "Indian Elections : Reaching the End of the Democratic Tether." Esprit, \%:75-87.

Jensenius, Francesca. 2013. "Who are Indian MLAs" in "Power, Performance and Bias: Evaluating the Electoral Quotas for Scheduled Castes in India." 55-71.

Kenny, Charles. 2010. "Publishing Construction Contracts and Outcome Details." World Bank Policy Research Working Paper.

Khemani, Stuti. 2004. "Political Cycles in a Developing Economy: Effect of Elections in the Indian States." Journal of Development Economics, 73 (1), pp. 125-154.

Khwaja, Asim and Atif Mian. 2005. "Do Lenders Favor Politically Connected Firms? Rent Provision in an Emerging Market." The Quarterly Journal of Economics, 120 (4): 1371-1411.

Kremer, Michael. 1993. "The O-Ring Theory of Economic Development." The Quarterly Journal of Economics, 108 (3): 551-575.

Krishnan, K.P. and T.V. Somanathan . 2013. "The Civil Service in the 21st Century." in Devesh Kapur and Pratap Bhanu Mehta, eds., Building an Indian State for the 21st Century.

Lee, David S. 2008. "Randomized Experiments from Non-Random Selection in US House Elections." Journal of Econometrics, 142 (2): 675-697.

Lee, David and Thomas Lemieux. 2010. "Regression Discontinuity Designs in Economics." Journal of Economic Literature, 48 (2): 281-355.

Lee, David, Enrico, Moretti and Matthew, Butler. 2004. "Do Voters Affect or Elect Policies? Evidence From the U.S. House." The Quarterly Journal of Economics, 119 (3): 807-859.

Lehne, Jonathan, Jacob N. Shapiro and Oliver Vanden Eynde. 2016. "Building Connections: Political Corruption and Road Construction in India." Working Paper.

Martinez-Bravo, Monica. 2014. "Educate to Lead? The Local Political Economy Effects of School Construction in Indonesia." Working Paper. 
McCrary, Justin. 2008. "Manipulation of the Running Variable in the Regression Discontinuity Design: A Density Test." Journal of Econometrics., 142 (2): 698-714.

Meyersson, Erick. 2014. "Islamic Rule and the Empowerment of the Poor and Pious." Econometrica, $82(1): 229-269$.

Min, Brain and Miriam Golden. 2014. "Electoral Cycles in Electricity Losses in India." Energy Policy, 65: 619-625.

Nath, Anusha. 2014. "Bureaucrats and Politicians: How Does Electoral Competition Affect Bureaucratic Performance?" Unpublished Manuscript.

Nagavarapu, Sriniketh and Sheetal Sekhri. 2014. "Less Is More? Implications of Regulatory Capture for Natural Resource Depletion." Working Paper.

Niehaus, Paul and Sandip Sukhtankar. 2013. "Corruption Dynamics: The Golden Goose Effect." American Economic Journal: Economic Policy, 5 (4): 230-269.

Maxim L. Pinkovskiy. 2013. "Economic Discontinuities at Borders: Evidence from Satellite Data on Lights at Night." Working Paper.

Maxim L. Pinkovskiy and Xaier Sala-i-Martin. 2016. "Lights, Camera,....Income! Illuminating the National Accounts-Household Surveys Debate." forthcoming The Quarterly Journal of Economics.

Michalopoulos, Stelios and Elias Papaioannou. 2013. "Pre-colonial Ethnic Institutions and Contemporary African Development." Econometrica, 81 (1): 113-152.

Michalopoulos, Stelios and Elias Papaioannou. 2014. "National Institutions and Sub-national Development in Africa." Quarterly Journal of Economics, 129 (1): 151-213.

Porter, Jack. 2003. "Estimation in the Regression Discontinuity Model." Working Paper, Department of Economics, University of Wisconsin.

Robinson, James A. and Thierry Verdier. 2013. "The Political Economy of Clientelism." The Scandinavian Journal of Economics, 115 (2): 260-291. 
Schady, Norbert R. 2000. "The Political Economy of Expenditures by the Peruvian Social Fund (FONCODES), 1991-95." The American Political Science Review, 94 (2): 289-304.

Singh, Sanjeet. 2005. "Fighting Corruption in Developing Countries: Dimensions of the Problem in India." Paper prepared for Good Governance, Institutional Integrity and Human Resources Management for Road Administrations, Session 2, Integrity in the Road Sector, World Road Association.

Storeygard, Adam. 2014. "Farther on Down the Road: Transport Costs, Trade and Urban Growth in Sub-Saharan Africa.", Working Paper.

Sukhtankar, Sandip and Milan Vaishnav. 2015. "Corruption in India: Bridging Research Evidence and Policy Options." Brookings-NCAER India Policy Forum 2014.

Tiwari, Devesh. 2014. "Quality is in the Eye of the Beholder: Electoral Competition and Candidate Quality in India." Unpublished Manuscript.

Uppal, Yogesh. 2009. "The Disadvantaged Incumbents: Estimating Incumbency Effects in Indian State Legislatures." Public Choice, 138 (1-2): 9-27.

Vaishnav, Milan. 2011a. "Caste Politics, Credibility and Criminality: Political Selection in India." Working Paper, South Asia Program, Carnegie Endowment for International Peace.

Vaishnav, Milan. 2011b. "The Market for Criminality: Money, Muscle and Elections in India." Typescript, Department of Political Science, Columbia University.

Vaishnav, Milan. 2011c. "Doing Good by Doing Bad: Why Indian Voters Support Criminal Politicians." Typescript, Department of Political Science, Columbia University.

van der Weide et. al 2015. "How Valuable is Market Access? Evidence from the West Bank." Unpublished Manuscript.

Wade, Robert. 1982. "The System of Administrative and Political corruption: Canal Irrigation in South India." Journal of Development Studies, 18 (3): 287-328. 
TABLE 1-A

Descriptive Statistics of Dependent Variables

\begin{tabular}{|c|c|c|c|c|c|c|}
\hline & \multicolumn{3}{|c|}{ Overall Sample } & \multicolumn{3}{|c|}{ "RD Sample (IK bandwidth = 6.35) } \\
\hline Variables & Accused & Non-Accused & Difference & Accused & Non-Accused & Difference \\
\hline Growth of Night Lights in $t+1$ & $\begin{array}{c}2.04 \\
(1.73)\end{array}$ & $\begin{array}{c}2.43 \\
(2.39)\end{array}$ & $\begin{array}{l}-0.39 \\
(2.90)\end{array}$ & $\begin{array}{l}-1.25 \\
(2.94)\end{array}$ & $\begin{array}{c}1.79 \\
(2.92)\end{array}$ & $\begin{array}{l}-3.03 \\
(4.14)\end{array}$ \\
\hline Log of Night Lights in $t+1$ & $\begin{array}{l}11.03 \\
(0.04)\end{array}$ & $\begin{array}{l}11.01 \\
(0.04)\end{array}$ & $\begin{array}{c}0.02 \\
(0.06)\end{array}$ & $\begin{array}{l}10.82 \\
(0.07)\end{array}$ & $\begin{array}{l}11.02 \\
(0.06)\end{array}$ & $\begin{array}{l}-0.20 \\
(0.09)\end{array}$ \\
\hline Night Lights average over Election Term & $\begin{array}{l}151,926.80 \\
(4337.546)\end{array}$ & $\begin{array}{c}157,719.70 \\
(94841.109)\end{array}$ & $\begin{array}{l}-5,792.95 \\
(6480.777)\end{array}$ & $\begin{array}{l}125,072.90 \\
(5702.853)\end{array}$ & $\begin{array}{l}148,250.30 \\
(6663.625)\end{array}$ & $\begin{array}{c}-23,177.42^{\text {*** }} \\
(8742.17)\end{array}$ \\
\hline No. of observations & 1915 & 1701 & & 810 & 771 & \\
\hline Length of Roads built under PMGSY (kms) & $\begin{array}{l}20.37 \\
(0.86)\end{array}$ & $\begin{array}{l}20.48 \\
(0.92)\end{array}$ & $\begin{array}{l}-0.10 \\
(1.26)\end{array}$ & $\begin{array}{l}20.25 \\
(1.21)\end{array}$ & $\begin{array}{l}21.21 \\
(1.38)\end{array}$ & $\begin{array}{l}-0.97 \\
(1.83)\end{array}$ \\
\hline
\end{tabular}

NOTES: The number of observations for the dependent variables are observed for each year of the election term. This is equivalent to 4 observations for each included constituency. Standard errors are given in parentheses. Asterisks denote significance levels $\left({ }^{*}=.10,{ }^{* *}=.05,{ }^{* * *}=.01\right)$ 
TABLE 1-B

Descriptive Statistics of Pre-determined Characteristics

\begin{tabular}{|c|c|c|c|c|c|c|}
\hline \multirow[b]{2}{*}{ Variables } & \multicolumn{3}{|c|}{ Overall Sample } & \multicolumn{3}{|c|}{ RD Sample (IK bandwidth $=6.35)$} \\
\hline & Accused & Non-Accused & Difference & Accused & Non-Accused & Difference \\
\hline \multirow[t]{2}{*}{ Growth of Night Lights in Previous Year } & 15.95 & 30.81 & $-14.86^{* *}$ & 20.44 & 29.79 & -9.35 \\
\hline & $(3.37)$ & $(6.71)$ & $(7.23)$ & $(5.82)$ & $(8.64)$ & $(10.32)$ \\
\hline \multirow[t]{2}{*}{ Log of Night Lights in Previous Year } & 10.86 & 10.83 & 0.04 & 10.67 & 10.87 & -0.19 \\
\hline & $(0.07)$ & $(0.08)$ & $(0.11)$ & $(0.11)$ & $(0.10)$ & $(0.15)$ \\
\hline \multirow[t]{2}{*}{ Log Electorate Size in Previous Election } & 11.99 & 12.06 & $-0.07 * *$ & 12.06 & 12.10 & -0.04 \\
\hline & $(0.02)$ & $(0.02)$ & $(0.03)$ & $(0.03)$ & $(0.03)$ & $(0.04)$ \\
\hline \multirow[t]{2}{*}{ Log Number Voted in Previous Election } & 11.54 & 11.61 & $-0.07^{* * *}$ & 11.60 & 11.64 & -0.04 \\
\hline & $(0.02)$ & $(0.02)$ & $(0.03)$ & $(0.03)$ & $(0.02)$ & $(0.04)$ \\
\hline \multirow[t]{2}{*}{ Turnout in Previous Election } & 64.32 & 64.42 & -0.09 & 63.99 & 64.22 & -0.23 \\
\hline & $(0.47)$ & $(0.54)$ & $(0.71)$ & $(0.72)$ & $(0.81)$ & $(1.08)$ \\
\hline \multirow[t]{2}{*}{ SC Constituency } & 0.11 & 0.13 & -0.03 & 0.14 & 0.09 & 0.05 \\
\hline & $(0.01)$ & $(0.02)$ & $(0.02)$ & $(0.02)$ & $(0.02)$ & $(0.03)$ \\
\hline \multirow[t]{2}{*}{ ST Constituency } & 0.05 & 0.05 & 0.00 & 0.03 & 0.03 & 0.00 \\
\hline & $(0.01)$ & $(0.01)$ & $(0.01)$ & $(0.01)$ & $(0.01)$ & $(0.02)$ \\
\hline \multirow{2}{*}{ Ruling Party in Previous Election } & 0.52 & 0.57 & -0.05 & 0.52 & 0.51 & 0.02 \\
\hline & $(0.02)$ & $(0.02)$ & $(0.03)$ & $(0.03)$ & $(0.04)$ & $(0.05)$ \\
\hline \multirow[t]{2}{*}{ Incumbent in Previous Election } & 0.36 & 0.44 & $-0.08^{* *}$ & 0.30 & 0.39 & $-0.09^{*}$ \\
\hline & $(0.02)$ & $(0.02)$ & $(0.03)$ & $(0.03)$ & $(0.03)$ & $(0.05)$ \\
\hline \multirow[t]{2}{*}{ Winner's Gender in Previous Election } & 0.07 & 0.05 & 0.02 & 0.09 & 0.06 & 0.04 \\
\hline & $(0.01)$ & $(0.01)$ & $(0.02)$ & $(0.02)$ & $(0.02)$ & $(0.03)$ \\
\hline \multirow[t]{2}{*}{ Runner-up's Gender in Previous Election } & 0.07 & 0.05 & 0.02 & 0.07 & 0.04 & 0.03 \\
\hline & $(0.01)$ & $(0.01)$ & $(0.02)$ & $(0.02)$ & $(0.01)$ & $(0.02)$ \\
\hline No. of observations & 502 & 437 & & 209 & 198 & \\
\hline Length of Roads built under PMGSY (kms) in Previous Year & $\begin{array}{c}8.88 \\
(0.56)\end{array}$ & $\begin{array}{c}9.68 \\
(0.73)\end{array}$ & $\begin{array}{l}-0.80 \\
(0.92)\end{array}$ & $\begin{array}{c}8.08 \\
(0.65)\end{array}$ & $\begin{array}{c}9.63 \\
(0.97)\end{array}$ & $\begin{array}{l}-1.55 \\
(1.17)\end{array}$ \\
\hline No. of observations & 213 & 213 & & 96 & 98 & \\
\hline
\end{tabular}

NOTES: The number of observations are from the previous election. This is equivalent to 1 observation per included constituency. Standard errors are given in parentheses. Asterisks denote significance levels $(*=.10, * *=.05, * * *=.01)$ 
TABLE 1-C

Descriptive Statistics of Criminal Accusations

\begin{tabular}{|c|c|c|c|c|c|c|c|c|}
\hline \multirow[b]{2}{*}{ Variables } & \multicolumn{4}{|c|}{ Overall Sample } & \multicolumn{4}{|c|}{ RD Sample (IK bandwidth = 6.35) } \\
\hline & All & Winners & Runners-up & Difference & All & Winners & Runners-up & Difference \\
\hline \multirow[t]{2}{*}{ Any case, proportion } & 0.50 & 0.53 & 0.47 & $0.07 * * *$ & 0.50 & 0.51 & 0.49 & 0.03 \\
\hline & $(0.01)$ & $(0.02)$ & $(0.02)$ & $(0.02)$ & $(0.02)$ & $(0.02)$ & $(0.02)$ & $(0.04)$ \\
\hline \multirow[t]{2}{*}{ Any serious case, proportion } & 0.37 & 0.40 & 0.35 & $0.06^{* *}$ & 0.38 & 0.38 & 0.38 & 0.00 \\
\hline & $(0.01)$ & $(0.02)$ & $(0.02)$ & $(0.02)$ & $(0.02)$ & $(0.02)$ & $(0.02)$ & $(0.03)$ \\
\hline \multirow[t]{2}{*}{ Any financial case, proportion } & 0.18 & 0.19 & 0.16 & $0.03^{*}$ & 0.17 & 0.16 & 0.18 & -0.02 \\
\hline & $(0.01)$ & $(0.01)$ & $(0.01)$ & $(0.02)$ & $(0.01)$ & $(0.02)$ & $(0.02)$ & $(0.03)$ \\
\hline \multirow[t]{2}{*}{ Multiple charges $(>1)$, proportion } & 0.24 & 0.27 & 0.21 & $0.06^{* * *}$ & 0.24 & 0.24 & 0.25 & 0.00 \\
\hline & $(0.01)$ & $(0.01)$ & $(0.01)$ & $(0.02)$ & $(0.02)$ & $(0.02)$ & $(0.02)$ & $(0.03)$ \\
\hline \multirow[t]{2}{*}{ Avg. number of serious charges } & 1.33 & 1.47 & 1.19 & $0.28^{*}$ & 1.52 & 1.56 & 1.49 & 0.08 \\
\hline & $(0.08)$ & $(0.11)$ & $(0.12)$ & $(0.16)$ & $(0.16)$ & $(0.21)$ & $(0.25)$ & $(0.33)$ \\
\hline \multirow[t]{2}{*}{ Avg. number of financial charges } & 0.18 & 0.19 & 0.16 & $0.03^{*}$ & 0.17 & 0.16 & 0.18 & -0.02 \\
\hline & $(0.01)$ & $(0.01)$ & $(0.01)$ & $(0.02)$ & $(0.01)$ & $(0.02)$ & $(0.02)$ & $(0.03)$ \\
\hline No. of observations & 1882 & 941 & 941 & & 814 & 407 & 407 & \\
\hline
\end{tabular}

NOTES: Standard errors are given in parentheses. Asterisks denote significance levels $\left(*=.10,{ }^{* *}=.05,{ }^{* * *}=.01\right)$ 
TABLE 2

Effect of Electing Criminally Accused Politicians on Growth of Night Lights

\begin{tabular}{lcccc}
\hline \hline Dependent Variable & \multicolumn{4}{c}{ Growth of Night Lights } \\
\hline Criminally Accused & $(1)$ & $(2)$ & $(3)$ & $(4)$ \\
& $-21.74^{* *}$ & $-20.08^{* *}$ & $-23.95^{*}$ & $-12.44^{* *}$ \\
& $(8.83)$ & $(8.07)$ & $(13.28)$ & $(5.50)$ \\
Bandwidth Size & 6.35 & 7.32 & 3.17 & 12.70 \\
No. of observations & 1,581 & 1,728 & 783 & 2,543 \\
\hline State and Year Fixed Effects & YES & YES & YES & YES \\
Bandwidth Type & IK (h) & CCT & h/2 & $2 \mathrm{~h}$ \\
Polynomial order of control function & \multicolumn{5}{c}{ Local Linear } \\
\hline \hline
\end{tabular}

NOTES: Standard errors are clustered at the constituency level and given in parentheses. The dependent variable is the residual from the regression of year growth of night lights on state and year dummies. Criminally accused is a dummy variable that is 1 if a criminally accused candidate wins against a non-accused candidate and 0 if criminally accused candidate loses against a non-accused candidate. The RD estimates in columns (1)-(4) are on a local linear regression using a triangular kernel. Asterisks denote significance levels $\left(*=.10,{ }^{* *}=.05,{ }^{* * *}=.01\right)$ 
TABLE 3

Effect of Electing Criminally Accused Politicians by Accusation Type

\begin{tabular}{|c|c|c|c|c|c|c|c|c|}
\hline \multirow{3}{*}{$\begin{array}{l}\text { Dependent Variable } \\
\text { Type of Accusation }\end{array}$} & \multicolumn{8}{|c|}{ Growth of Night Lights } \\
\hline & \multicolumn{4}{|c|}{ Financial Charge } & \multicolumn{4}{|c|}{ Non-Financial Charge } \\
\hline & $(1)$ & $(2)$ & $(3)$ & $(4)$ & $(5)$ & $(6)$ & $(7)$ & $(8)$ \\
\hline & \multicolumn{8}{|c|}{ PANEL A } \\
\hline Local Linear & $\begin{array}{c}-39.39 * * * \\
(14.50)\end{array}$ & $\begin{array}{c}-36.00^{* * *} \\
(13.78)\end{array}$ & $\begin{array}{c}-38.62^{* *} \\
(18.84)\end{array}$ & $\begin{array}{c}-21.60^{* *} \\
(9.74)\end{array}$ & $\begin{array}{l}-9.51 \\
(8.18)\end{array}$ & $\begin{array}{l}-9.71 \\
(8.77)\end{array}$ & $\begin{array}{l}-15.76 \\
(14.13)\end{array}$ & $\begin{array}{l}-3.01 \\
(4.97)\end{array}$ \\
\hline Bandwidth Size & 7.72 & 8.41 & 3.86 & 15.44 & 8.97 & 8.19 & 4.48 & 17.94 \\
\hline \multirow[t]{2}{*}{ No. of observations } & 611 & 653 & 306 & 958 & 1,332 & 1,249 & 724 & 1,976 \\
\hline & \multicolumn{8}{|c|}{ PANEL B } \\
\hline Type of Accusation & \multicolumn{4}{|c|}{ Serious Charge } & \multicolumn{4}{|c|}{ Non-Serious Charge } \\
\hline Local Linear & $\begin{array}{c}-33.19 * * * \\
(11.75)\end{array}$ & $\begin{array}{c}-29.81^{* * *} \\
(10.23)\end{array}$ & $\begin{array}{l}-29.39^{*} \\
(15.93)\end{array}$ & $\begin{array}{c}-18.67^{* *} \\
(7.53)\end{array}$ & $\begin{array}{l}8.46 \\
(6.54)\end{array}$ & $\begin{array}{l}7.93 \\
(6.33)\end{array}$ & $\begin{array}{c}5.96 \\
(7.97)\end{array}$ & $\begin{array}{l}-0.18 \\
(4.63)\end{array}$ \\
\hline Bandwidth Size & 5.49 & 6.78 & 2.75 & 10.99 & 7.38 & 7.78 & 3.69 & 14.75 \\
\hline No. of observations & 1,070 & 1,257 & 506 & 1,729 & 422 & 426 & 226 & 707 \\
\hline State and Year Fixed Effects & YES & YES & YES & YES & YES & YES & YES & YES \\
\hline Bandwidth Type & $\operatorname{IK}(\mathrm{h})$ & $\mathrm{CCT}$ & $\mathrm{h} / 2$ & $2 \mathrm{~h}$ & $\mathrm{IK}(\mathrm{h})$ & $\mathrm{CCT}$ & $\mathrm{h} / 2$ & $2 \mathrm{~h}$ \\
\hline
\end{tabular}

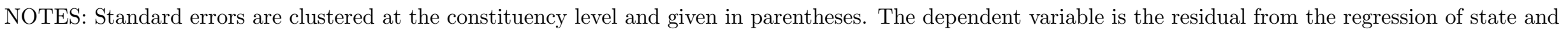

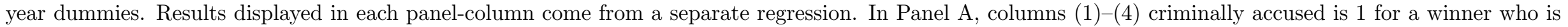

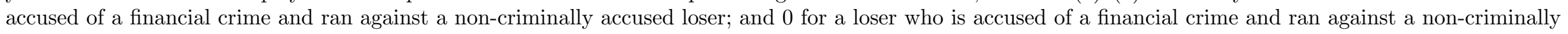

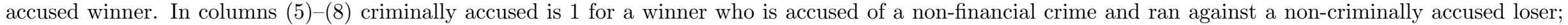

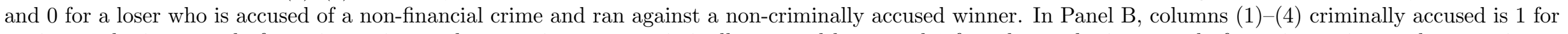

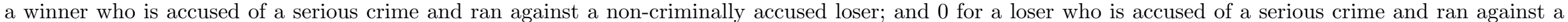

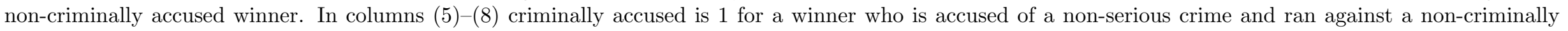

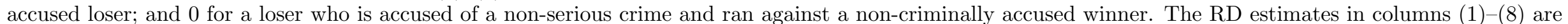
on a local linear regression using a triangular kernel. Asterisks denote significance levels $\left(*=.10,{ }^{* *}=.05, * * *=.01\right)$ 
TABLE 4

Effect of Electing Criminally Accused Politicians by Multiple Cases

\begin{tabular}{|c|c|c|c|c|c|c|c|c|}
\hline \multirow{3}{*}{$\begin{array}{l}\text { Dependent Variable } \\
\text { Type of Accusation }\end{array}$} & \multicolumn{8}{|c|}{ Growth of Night Lights } \\
\hline & \multicolumn{4}{|c|}{ Multiple Cases $(>=2)$} & \multicolumn{4}{|c|}{ Multiple Cases $(>=5)$} \\
\hline & $(1)$ & $(2)$ & $(3)$ & $(4)$ & $(5)$ & $(6)$ & $(7)$ & $(8)$ \\
\hline Local Linear & $\begin{array}{c}-30.91^{* * *} \\
(10.36)\end{array}$ & $\begin{array}{c}-29.52^{* * *} \\
(10.08)\end{array}$ & $\begin{array}{l}-28.50 * * \\
(12.61)\end{array}$ & $\begin{array}{c}-18.51^{* *} \\
(7.23)\end{array}$ & $\begin{array}{c}-42.62^{* *} \\
(20.16)\end{array}$ & $\begin{array}{c}-38.92^{* *} \\
(19.28)\end{array}$ & $\begin{array}{c}-51.83^{* *} \\
(26.05)\end{array}$ & $\begin{array}{c}-28.53^{* *} \\
(14.28)\end{array}$ \\
\hline Bandwidth Size & 6.96 & 7.39 & 3.48 & 13.93 & 7.83 & 8.71 & 3.92 & 15.66 \\
\hline No. of observations & 815 & 842 & 413 & 1,245 & 238 & 253 & 122 & 351 \\
\hline State and Year Fixed Effects & YES & YES & YES & YES & YES & YES & YES & YES \\
\hline Bandwidth Type & $\mathrm{IK}(\mathrm{h})$ & $\mathrm{CCT}$ & $\mathrm{h} / 2$ & $2 \mathrm{~h}$ & $\mathrm{IK}(\mathrm{h})$ & $\mathrm{CCT}$ & $\mathrm{h} / 2$ & $2 \mathrm{~h}$ \\
\hline
\end{tabular}

NOTES: Standard errors are clustered at the constituency level and given in parentheses. The dependent variable is the residual from the regression of state and year dummies. Results displayed in each column come from a separate regression. In columns (1)-(4) criminally accused is 1 for a candidate who is accused of 2 or more criminal cases; and 0 otherwise. In columns (5)-(8), criminally accused is 1 for a candidate who is accused accused of 5 or more criminal cases. The RD 
TABLE 5

Effect of Electing Criminally Accused Politicians by Year in Power

\begin{tabular}{|c|c|c|c|c|c|c|c|c|}
\hline \multirow[t]{2}{*}{ Dependent Variable } & \multicolumn{4}{|c|}{$\log \left(Y_{i s t+1}\right)-\log \left(Y_{i s t}\right)$} & \multicolumn{4}{|c|}{$\log \left(Y_{i s t+2}\right)-\log \left(Y_{i s t}\right)$} \\
\hline & $(1)$ & $(2)$ & $(3)$ & $(4)$ & $(5)$ & $(6)$ & $(7)$ & $(8)$ \\
\hline & \multicolumn{8}{|c|}{ PANEL A } \\
\hline Criminally Accused & $\begin{array}{l}-3.51 \\
(7.91)\end{array}$ & $\begin{array}{l}-3.36 \\
(8.26)\end{array}$ & $\begin{array}{c}-6.33 \\
(10.30)\end{array}$ & $\begin{array}{c}1.03 \\
(5.85)\end{array}$ & $\begin{array}{c}-10.44 \\
(10.41)\end{array}$ & $\begin{array}{c}-9.94 \\
(10.27)\end{array}$ & $\begin{array}{c}-8.78 \\
(14.30)\end{array}$ & $\begin{array}{l}-10.71 \\
(7.95)\end{array}$ \\
\hline Bandwidth Size & 9.71 & 7.85 & 4.86 & 19.42 & 7.3 & 7.85 & 3.65 & 14.59 \\
\hline No. of observations & 552 & 473 & 304 & 809 & 442 & 501 & 234 & 695 \\
\hline Dependent Variable & \multicolumn{4}{|c|}{$\log \left(Y_{i s t+3}\right)-\log \left(Y_{i s t}\right)$} & \multicolumn{4}{|c|}{$\log \left(Y_{i s t+4}\right)-\log \left(Y_{i s t}\right)$} \\
\hline & \multicolumn{8}{|c|}{ PANEL B } \\
\hline Criminally Accused & $\begin{array}{c}-57.67^{*} \\
(30.77)\end{array}$ & $\begin{array}{c}-45.87^{*} \\
(23.50)\end{array}$ & $\begin{array}{c}-46.1 \\
(31.07)\end{array}$ & $\begin{array}{l}-36.71^{*} \\
(21.11)\end{array}$ & $\begin{array}{c}-101.05^{* *} \\
(41.36)\end{array}$ & $\begin{array}{c}-80.12^{* *} \\
(33.50)\end{array}$ & $\begin{array}{c}-104.09 * \\
(60.03)\end{array}$ & $\begin{array}{c}-58.47^{* *} \\
(26.03)\end{array}$ \\
\hline Bandwidth Size & 4.69 & 7.85 & 2.34 & 9.38 & 5.61 & 7.85 & 2.8 & 11.22 \\
\hline No. of observations & 289 & 438 & 144 & 528 & 331 & 423 & 157 & 548 \\
\hline State and Year Fixed Effects & YES & YES & YES & YES & YES & YES & YES & YES \\
\hline Bandwidth Type & IK $(h)$ & $\mathrm{CCT}$ & $\mathrm{h} / 2$ & $2 \mathrm{~h}$ & IK $(\mathrm{h})$ & $\mathrm{CCT}$ & $\mathrm{h} / 2$ & $2 \mathrm{~h}$ \\
\hline Polynomial order of control function & \multicolumn{8}{|c|}{ Local Linear } \\
\hline
\end{tabular}

NOTES: Standard errors are clustered at the constituency level and given in parentheses. The dependent variable is the residual from the regression of state and year dummies. Criminally accused is a dummy variable that is 1 if a criminally accused candidate wins against a non-accused candidate and 0 if criminally accused candidate loses against a non-accused candidate. The RD estimates in columns (1)-(8) are based on a local linear regression using a triangular kernel. Asterisks denote significance levels $(*=.10, * *=.05, * * *=.01)$ 


\section{TABLE 6}

Effect of Electing Criminally Accused Politicians by State Characteristics

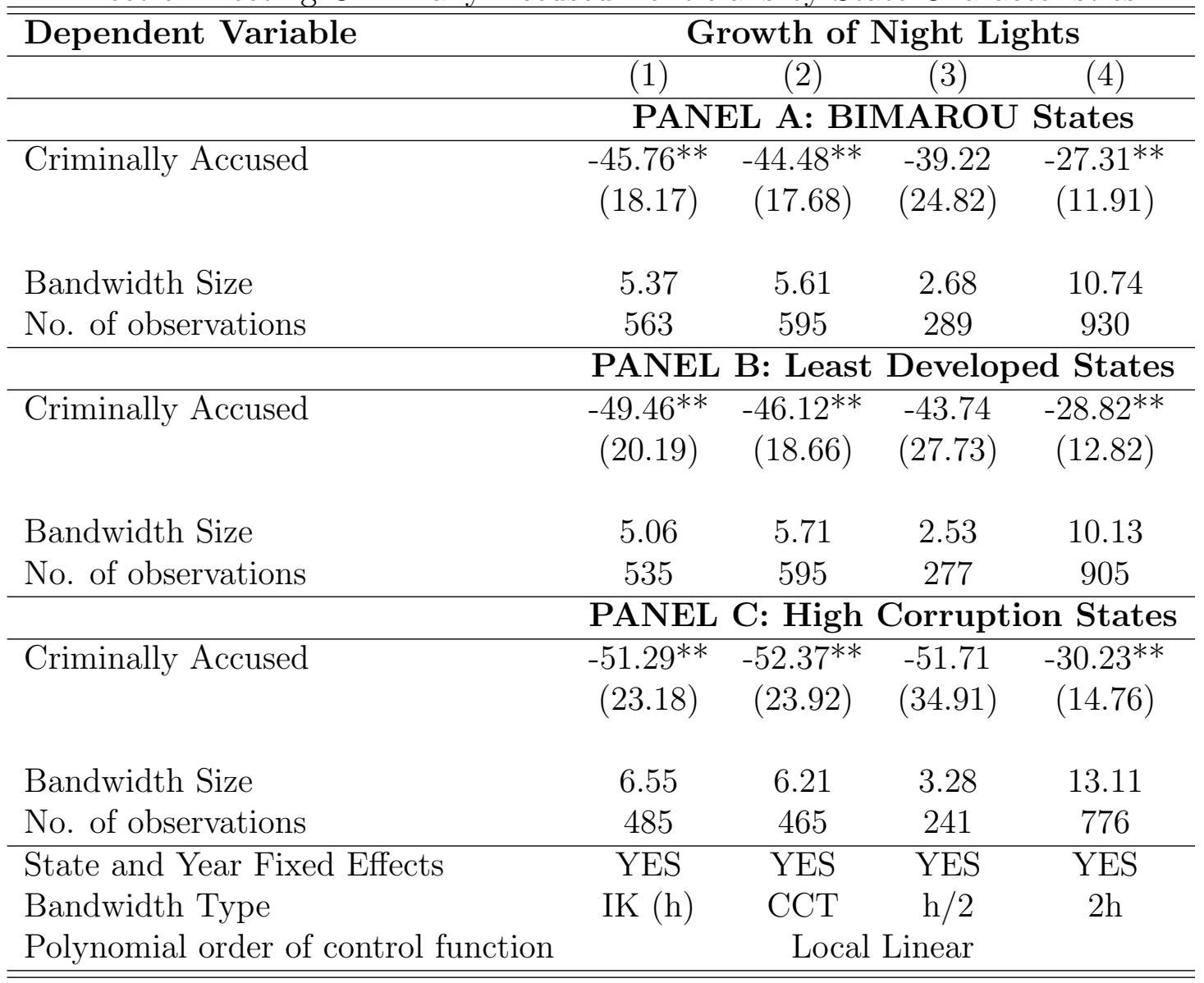

NOTES: Standard errors are clustered at the constituency level and given in parentheses. The dependent variable is the residual from the regression of state and year dummies. Results displayed in each column come year from a separate regression. Panel A includes the BIMAROU states: Bihar, Chattisgarh, Jharkhand, Orissa, Uttar Pradesh, and Uttarakhand; Panel B includes the Least Developed states as ranked by Ministry of Finance: Arunachal Pradesh, Assam, Bihar, Jharkhand, Odisha and Uttar Pradesh; and Panel C includes the High Corruption states as ranked by Transparency International India (TII) on index of corruption: Tamil Nadu, Haryana, Jharkhand, Assam, and Bihar. The RD estimates in columns (1)-(4) are on a local linear regression using a triangular kernel. Asterisks denote significance levels $(*=.10, * *=.05, * * *=.01)$ 


\section{TABLE 7}

Effect of Electing Criminally Accused Politicians on Roads

\begin{tabular}{|c|c|c|c|c|}
\hline \multirow[t]{2}{*}{ Dependent Variable } & \multicolumn{4}{|c|}{ Length of Roads Built (in kms) } \\
\hline & $(1)$ & $(2)$ & $(3)$ & (4) \\
\hline & \multicolumn{4}{|c|}{ PANEL A: All States } \\
\hline Criminally Accused & $\begin{array}{c}-9.11^{* *} \\
(4.01)\end{array}$ & $\begin{array}{c}-9.04^{* *} \\
(3.99)\end{array}$ & $\begin{array}{l}-2.64 \\
(4.44)\end{array}$ & $\begin{array}{c}-5.63^{*} \\
(3.05)\end{array}$ \\
\hline Bandwidth Size & 6.75 & 6.87 & 3.38 & 13.5 \\
\hline \multirow[t]{2}{*}{ No. of observations } & 532 & 535 & 255 & 818 \\
\hline & \multicolumn{4}{|c|}{ PANEL B: BIMAROU States } \\
\hline Criminally Accused & $\begin{array}{c}-16.17^{* *} \\
(6.98)\end{array}$ & $\begin{array}{c}-16.44^{* *} \\
(7.22)\end{array}$ & $\begin{array}{c}-10.95 \\
(7.53)\end{array}$ & $\begin{array}{c}-11.97^{* *} \\
(5.03)\end{array}$ \\
\hline Bandwidth Size & 7.92 & 7.35 & 3.96 & 15.83 \\
\hline \multirow[t]{2}{*}{ No. of observations } & 290 & 263 & 151 & 412 \\
\hline & \multicolumn{4}{|c|}{ PANEL C: Least Developed States } \\
\hline Criminally Accused & $\begin{array}{c}-17.24^{* *} \\
(7.32)\end{array}$ & $\begin{array}{c}-17.25^{* *} \\
(7.34)\end{array}$ & $\begin{array}{l}-9.33 \\
(7.73)\end{array}$ & $\begin{array}{c}-13.05^{* *} \\
(5.33)\end{array}$ \\
\hline Bandwidth Size & 7.39 & 7.34 & 3.69 & 14.78 \\
\hline \multirow[t]{2}{*}{ No. of observations } & 275 & 275 & 143 & 411 \\
\hline & \multicolumn{4}{|c|}{ PANEL D: High Corruption States } \\
\hline Criminally Accused & $\begin{array}{l}-0.72 \\
(6.54)\end{array}$ & $\begin{array}{c}1.1 \\
(7.67)\end{array}$ & $\begin{array}{c}0.47 \\
(10.10)\end{array}$ & $\begin{array}{c}4.09 \\
(4.60)\end{array}$ \\
\hline Bandwidth Size & 9.56 & 7.61 & 4.78 & 19.11 \\
\hline No. of observations & 203 & 166 & 114 & 284 \\
\hline State and Year Fixed Effects & YES & YES & YES & YES \\
\hline Bandwidth Type & $\mathrm{IK}(\mathrm{h})$ & $\mathrm{CCT}$ & $\mathrm{h} / 2$ & $2 \mathrm{~h}$ \\
\hline Polynomial order of control function & \multicolumn{4}{|c|}{ Local Linear } \\
\hline
\end{tabular}

NOTES: Standard errors are clustered at the constituency level and given in parentheses. The dependent variable is the residual from the regression of state and year dummies. Results displayed in each column come year from a separate regression. Panel A includes all the states; Panel B includes the BIMAROU states: Bihar, Chattisgarh, Jharkhand, Orissa, Uttar Pradesh, and Uttarakhand; Panel C includes the Least Developed states as ranked by Ministry of Finance: Arunachal Pradesh, Assam, Bihar, Jharkhand, Odisha and Uttar Pradesh; and Panel D includes the High Corruption states as ranked by Transparency International India (TII) on index of corruption: Tamil Nadu, Haryana, Jharkhand, Assam, and Bihar. The RD estimates in columns (1)-(4) are on a local linear regression using a triangular kernel. Asterisks denote significance levels $\left({ }^{*}=.10,{ }^{* *}=.05,{ }^{* * *}=.01\right)$ 
TABLE 8

Effect of Electing Criminally Accused (Serious Charge) Politicians on Roads

\begin{tabular}{|c|c|c|c|c|}
\hline \multirow[t]{2}{*}{ Dependent Variable } & \multicolumn{4}{|c|}{ Length of Roads Built (in kms) } \\
\hline & (1) & $(2)$ & $(3)$ & $(4)$ \\
\hline & \multicolumn{4}{|c|}{ PANEL A: All States } \\
\hline Serious Charge & $\begin{array}{l}-8.85^{*} \\
(4.97)\end{array}$ & $\begin{array}{c}-8.99^{*} \\
(5.03)\end{array}$ & $\begin{array}{l}-3.74 \\
(5.50)\end{array}$ & $\begin{array}{l}-4.51 \\
(3.69)\end{array}$ \\
\hline Bandwidth Size & 6.99 & 6.73 & 3.5 & 13.99 \\
\hline \multirow[t]{2}{*}{ No. of observations } & 412 & 408 & 204 & 618 \\
\hline & \multicolumn{4}{|c|}{ PANEL B: BIMAROU States } \\
\hline Serious Charge & $\begin{array}{c}-16.44^{*} \\
(9.00)\end{array}$ & $\begin{array}{c}-16.54^{*} \\
(8.49)\end{array}$ & $\begin{array}{c}-5.57 \\
(7.33)\end{array}$ & $\begin{array}{c}-14.66^{* *} \\
(6.71)\end{array}$ \\
\hline Bandwidth Size & 5.69 & 6.94 & 2.84 & 11.38 \\
\hline \multirow[t]{2}{*}{ No. of observations } & 191 & 211 & 95 & 289 \\
\hline & \multicolumn{4}{|c|}{ PANEL C: Least Developed States } \\
\hline Serious Charge & $\begin{array}{c}-16.90^{* *} \\
(8.31)\end{array}$ & $\begin{array}{c}-16.90^{* *} \\
(8.54)\end{array}$ & $\begin{array}{l}-12.03 \\
(9.47)\end{array}$ & $\begin{array}{c}-11.59^{* *} \\
(5.82)\end{array}$ \\
\hline Bandwidth Size & 7.45 & 6.94 & 3.73 & 14.91 \\
\hline \multirow[t]{2}{*}{ No. of observations } & 243 & 225 & 134 & 345 \\
\hline & \multicolumn{4}{|c|}{ PANEL D: High Corruption States } \\
\hline Serious Charge & $\begin{array}{l}-1.74 \\
(7.99)\end{array}$ & $\begin{array}{l}-0.71 \\
(8.49)\end{array}$ & $\begin{array}{c}-3.79 \\
(11.12)\end{array}$ & $\begin{array}{c}0.23 \\
(5.35)\end{array}$ \\
\hline Bandwidth Size & 8.02 & 7.17 & 4.01 & 16.03 \\
\hline No. of observations & 154 & 139 & 85 & 217 \\
\hline State and Year Fixed Effects & YES & YES & YES & YES \\
\hline Bandwidth Type & IK $(\mathrm{h})$ & CCT & $\mathrm{h} / 2$ & $2 \mathrm{~h}$ \\
\hline Polynomial order of control function & \multicolumn{4}{|c|}{ Local Linear } \\
\hline
\end{tabular}

NOTES: Standard errors are clustered at the constituency level and given in parentheses. The dependent variable is the residual from the regression of state and year dummies. Results displayed in each column come year from a separate regression. Panel A includes all the states; Panel B includes the BIMAROU states: Bihar, Chattisgarh, Jharkhand, Orissa, Uttar Pradesh, and Uttarakhand; Panel C includes the Least Developed states as ranked by Ministry of Finance: Arunachal Pradesh, Assam, Bihar, Jharkhand, Odisha and Uttar Pradesh; and Panel D includes the High Corruption states as ranked by Transparency International India (TII) on index of corruption: Tamil Nadu, Haryana, Jharkhand, Assam, and Bihar. The RD estimates in columns (1)-(4) are on a local linear regression using a triangular kernel. Asterisks denote significance levels $\left({ }^{*}=.10,{ }^{* *}=.05,{ }^{* * *}=.01\right)$ 


\section{TABLE 9}

Effect of Electing Criminally Accused (Financial Charge) Politicians on Roads

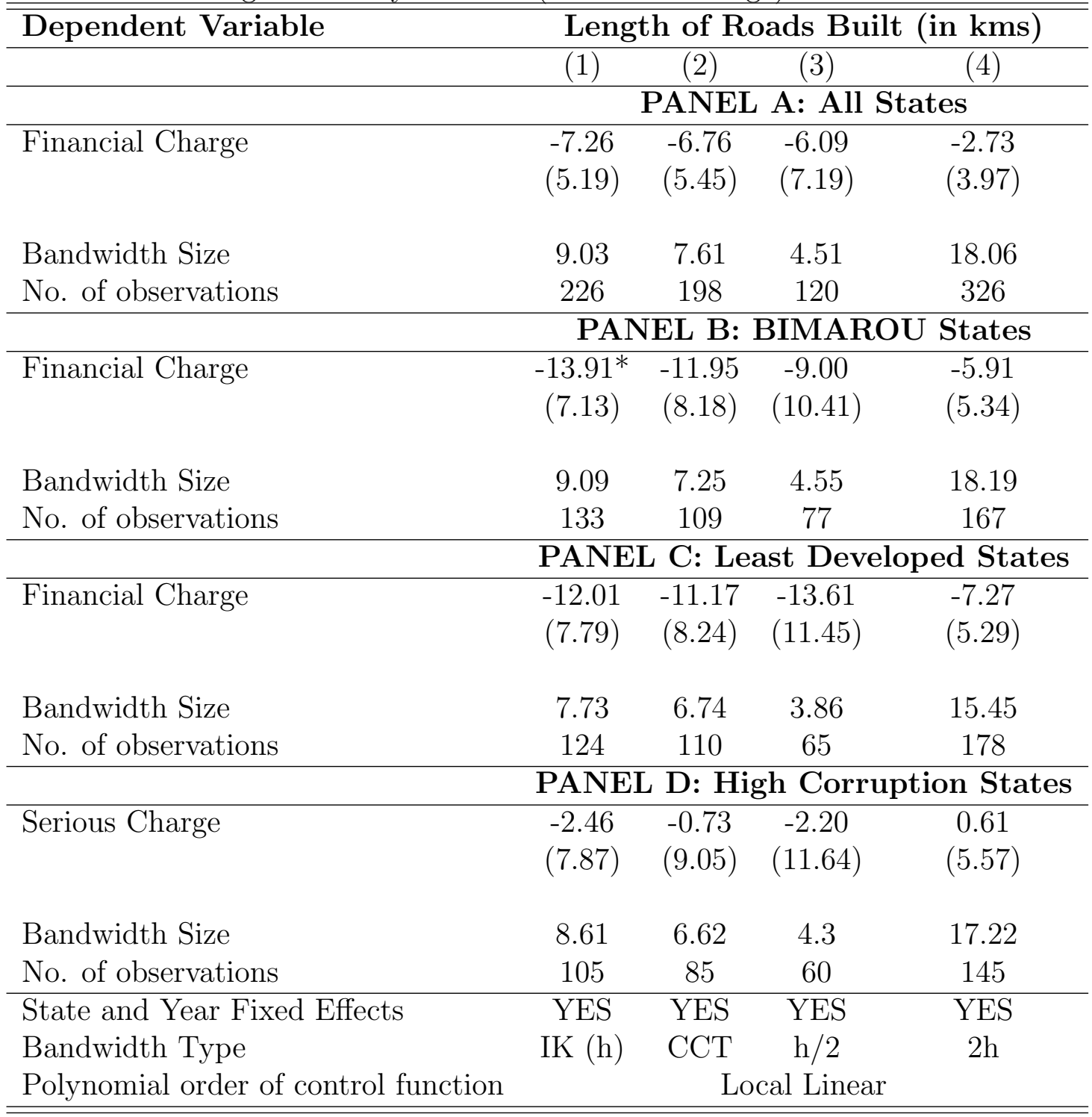

NOTES: Standard errors are clustered at the constituency level and given in parentheses. The dependent variable is the residual from the regression of state and year dummies. Results displayed in each column come year from a separate regression. Panel A includes all the states; Panel B includes the BIMAROU states: Bihar, Chattisgarh, Jharkhand, Orissa, Uttar Pradesh, and Uttarakhand; Panel C includes the Least Developed states as ranked by Ministry of Finance: Arunachal Pradesh, Assam, Bihar, Jharkhand, Odisha and Uttar Pradesh; and Panel D includes the High Corruption states as ranked by Transparency International India (TII) on index of corruption: Tamil Nadu, Haryana, Jharkhand, Assam, and Bihar. The RD estimates in columns (1)-(4) are on a local linear regression using a triangular kernel. Asterisks denote significance levels $\left({ }^{*}=.10,{ }^{* *}=.05,{ }^{* * *}=.01\right)$ 
TABLE 10

Effect of Electing Criminally Accused Politicians on Constituency GDP Growth

\begin{tabular}{|c|c|c|c|}
\hline \multirow[t]{2}{*}{ Dependent Variable } & \multicolumn{3}{|c|}{ Growth of Night Lights } \\
\hline & Baseline Estimate & Financial Charge & Serious Charge \\
\hline & $(1)$ & $(2)$ & $(3)$ \\
\hline & \multicolumn{3}{|c|}{ PANEL A } \\
\hline RD Estimate & $-21.74^{* *}$ & $-39.39 * * *$ & $-33.19 * * *$ \\
\hline Polynomial order of control function & \multicolumn{3}{|c|}{ Local Linear } \\
\hline Bandwidth type & \multicolumn{3}{|c|}{ Imbens-Kalyanaraman } \\
\hline & \multicolumn{3}{|c|}{ PANEL B } \\
\hline \multicolumn{4}{|c|}{ Estimated Effect on GDP Growth Rate (in percentage points) } \\
\hline Using global average (Henderson et al. 2014) & -6.5 & -11.8 & -10.0 \\
\hline Using India-specific average (Bickenback et al. 2014) & -2.3 & -4.2 & -3.6 \\
\hline \multicolumn{4}{|c|}{$\begin{array}{ll} & \text { PANEL C } \\
\end{array}$} \\
\hline \multicolumn{4}{|c|}{ Assuming 6\% growth - what would growth look like? } \\
\hline Upper Bound & 5.61 & 5.29 & 5.40 \\
\hline Lower Bound & 5.86 & 5.75 & 5.78 \\
\hline
\end{tabular}

NOTES: The definition of the main explanatory variable changes across the columns: criminally accused, financial criminal accusation, and serious criminal accusation. Column (1) reports the RD estimate for criminally accused from Table 2, Column (1). In Column (2), we report the RD estimate for any financial charge from Column (1) of Table 3 in Panel A, while we report the RD estimate for any serious charge from Column (1) of Table 3 in Panel B in Column (3) of this table. The upper-bound uses an elasticity of 0.3 . The lower bound uses an elasticity of 0.107 . 
Figure 1

Continuity of the Victory Margin between Criminally Accused and Non-Accused

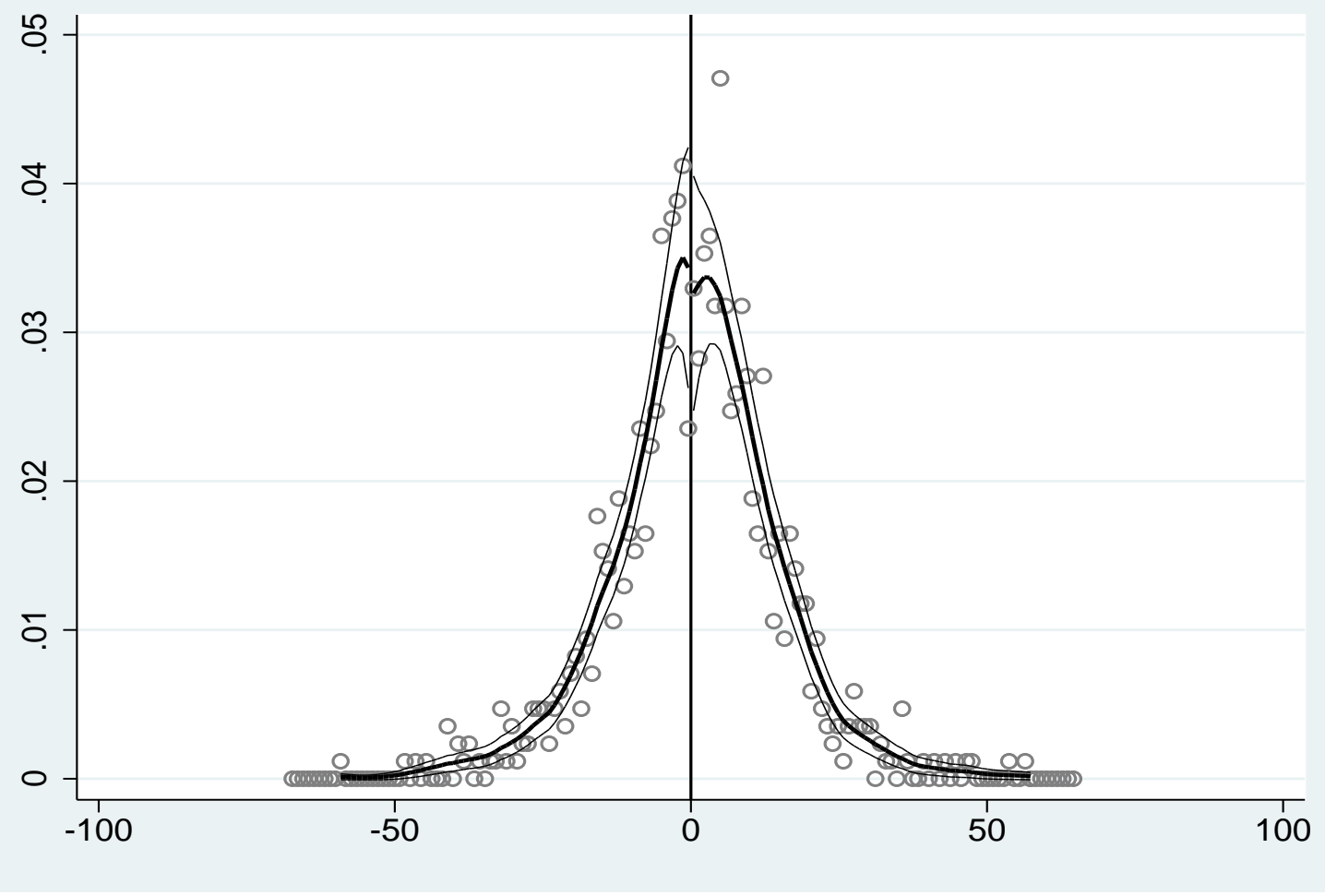

(a) McCrary Test

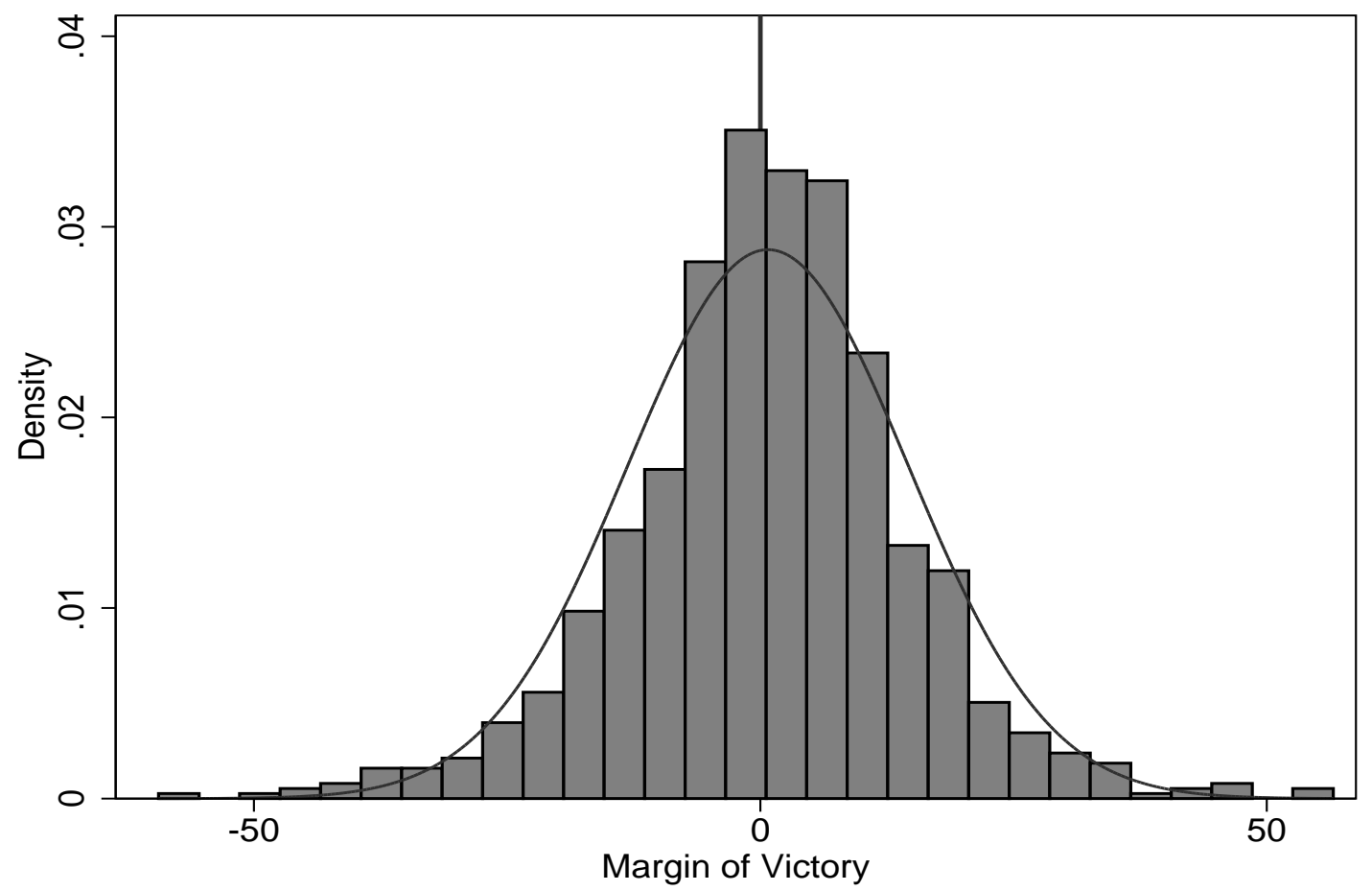

(b) Density of the Victory Margin

The forcing variable is the margin of victory of a criminally-accused candidate. Negative values are the difference in the vote shares of a criminally-accused runners-up and a non-accused winner. Positive values are the differences in the vote shares of a criminally-accused winner and a non-accused runners-up. The estimated size of discontinuity in margin of victory (log difference in height) is -0.061 ( $\mathrm{se}=0.2$ ). 
Figure 2

Balance Test for Constituency Characteristics

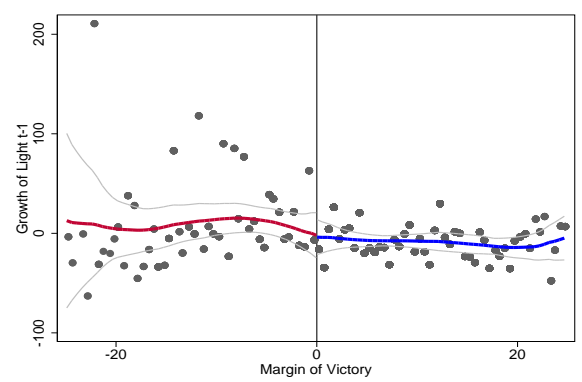

(a) Growth of Light t-1

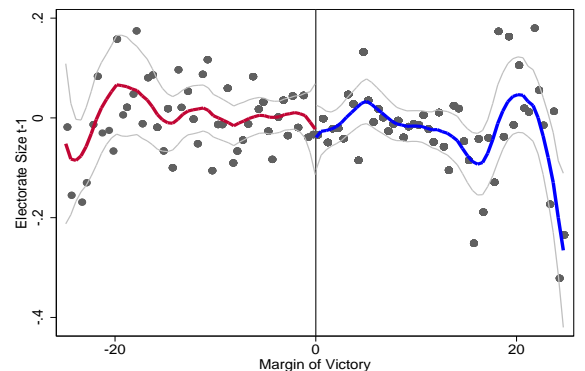

(c) Electorate Size t-1

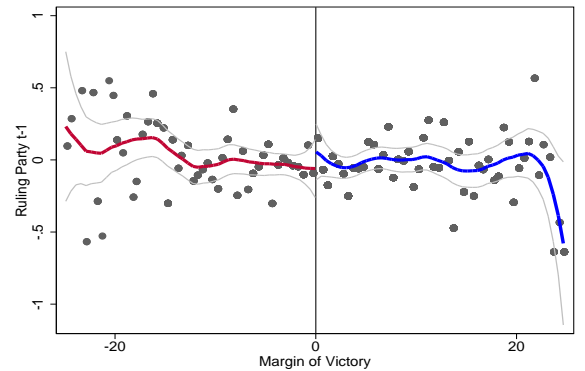

(e) Ruling Party t-1

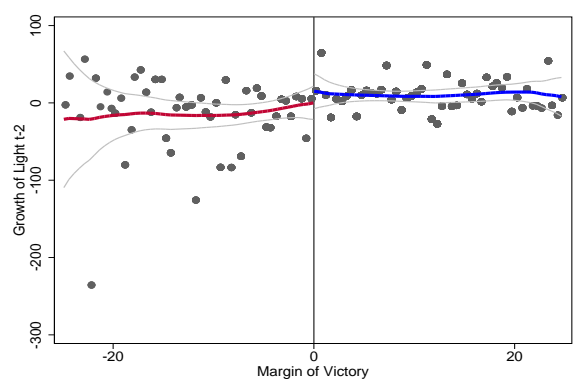

(b) Growth of Light t-2

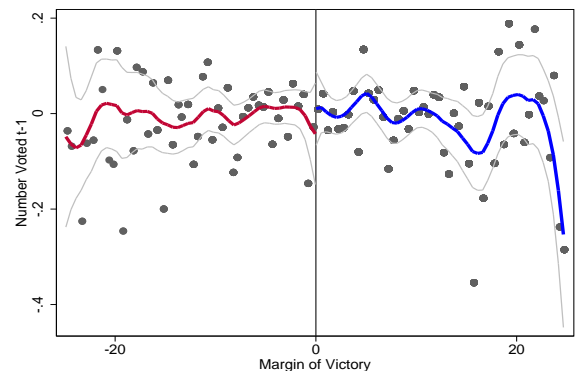

(d) Number Voted t-1

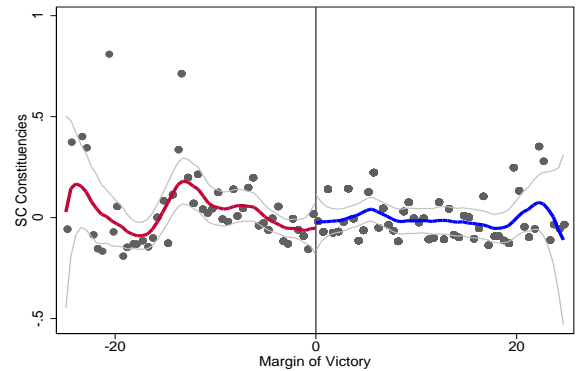

(f) SC Constituencies

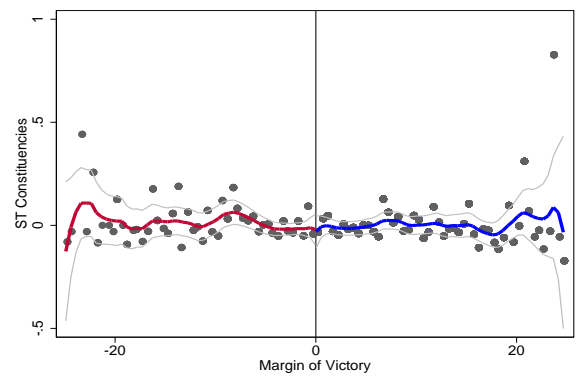

(g) ST Constituencies

The forcing variable is the margin of victory of a criminally-accused candidate. Negative values are the difference in the vote shares of a criminally-accused runners-up and a non-accused winner. Positive values are the differences in the vote shares of a criminally-accused winner and a non-accused runners-up. Each variable on the y-axis is net of state and year fixed effects. The dots in the scatter plot depict the averages over each successive interval of $0.5 \%$ of margin of victory. The curves are local linear regressions fit separately for positive and negative margins of victory using a triangular kernel and an optimal bandwidth calculator as suggested in Imbens and Kalayanaraman (2012). The confidence intervals are the $95 \%$ confidence intervals plotted using standard errors that are clustered at the constituency level. 
Figure 3

Balance Test for Candidate Characteristics

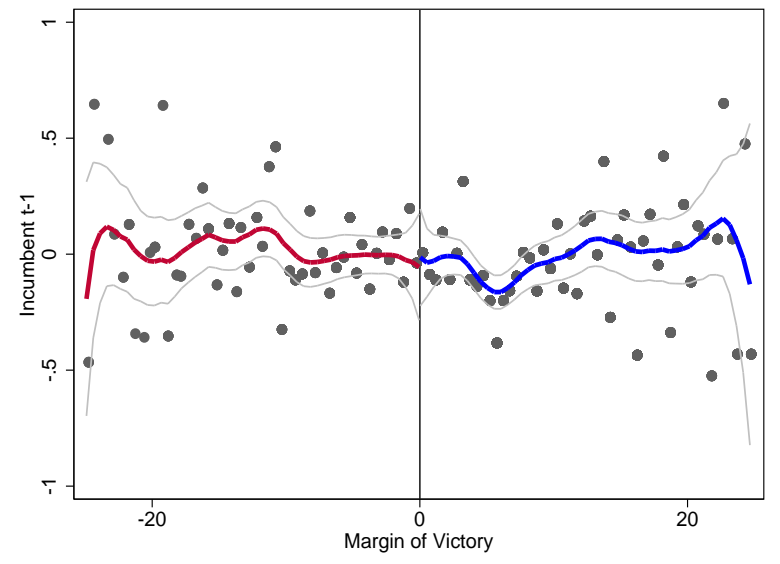

(a) Incumbent in t-1

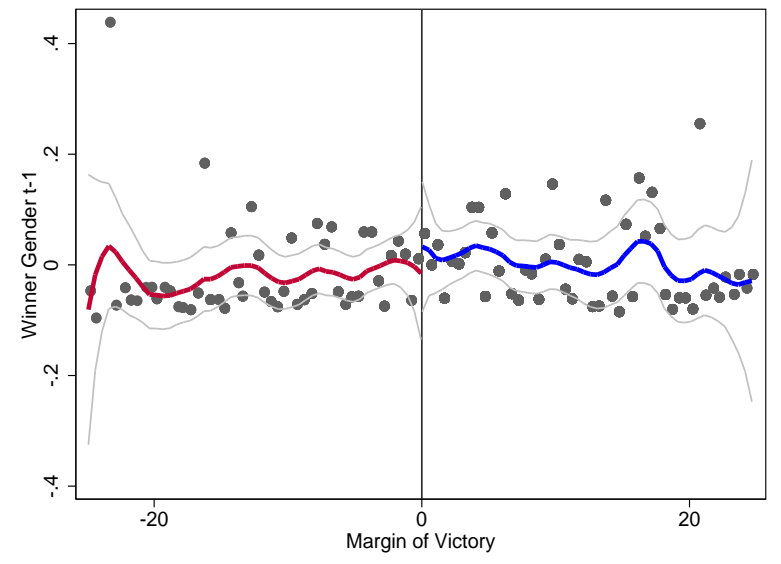

(b) Winners Gender t-1

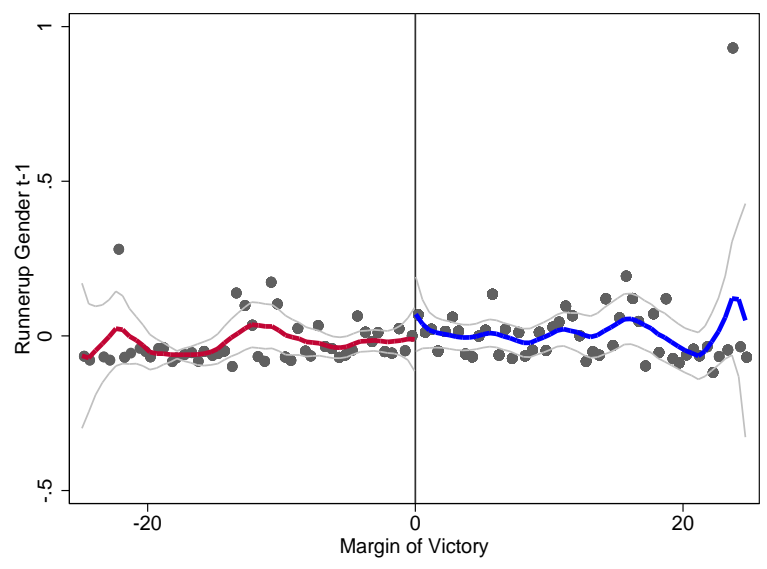

(c) Runners-Up Gender t-1

The forcing variable is the margin of victory of a criminally-accused candidate. Negative values are the difference in the vote shares of a criminally-accused runners-up and a non-accused winner. Positive values are the differences in the vote shares of a criminally-accused winner and a non-accused runners-up. Each variable on the y-axis is net of state and year fixed effects. The dots in the scatter plot depict the averages over each successive interval of $0.5 \%$ of margin of victory. The curves are local linear regressions fit separately for positive and negative margins of victory using a triangular kernel and an optimal bandwidth calculator as suggested in Imbens and Kalayanaraman (2012). The confidence intervals are the $95 \%$ confidence intervals plotted using standard errors that are clustered at the constituency level. 
Figure 4

Effect of Electing Criminally Accused Politicians on Growth of Night Lights

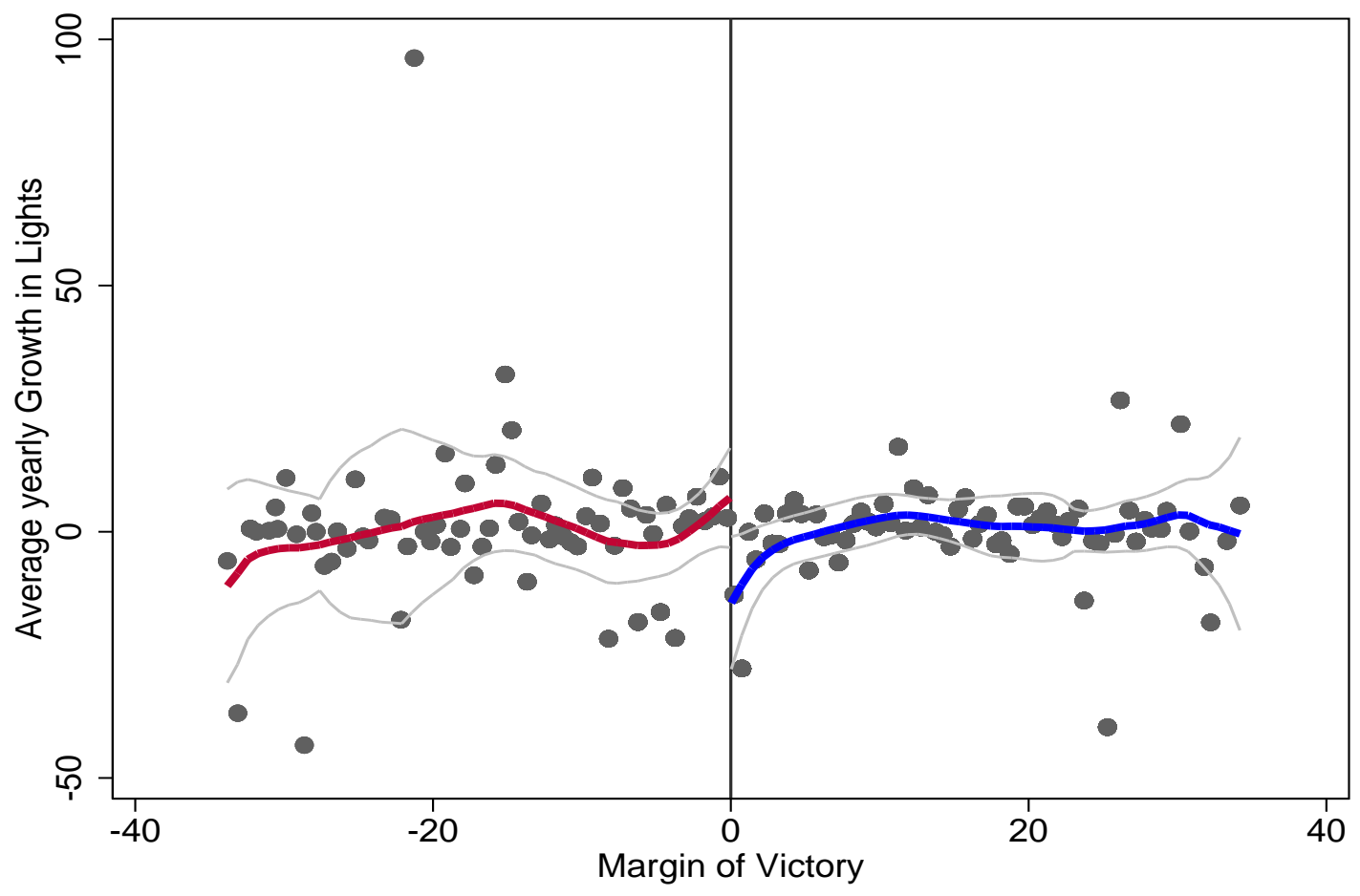

The forcing variable is the margin of victory of a criminally-accused candidate. Negative values are the difference in the vote shares of a criminally-accused runners-up and a non-accused winner. Positive values are the differences in the vote shares of a criminally-accused winner and a non-accused runners-up. The variable on the y-axis is the growth of night lights net of state and year fixed effects. The dots in the scatter plot depict the average of growth of night lights over each successive interval of $0.5 \%$ of margin of victory. The curves are local linear regressions fit separately for positive and negative margins of victory using a triangular kernel and an optimal bandwidth calculator as suggested in Imbens and Kalayanaraman (2012). The confidence intervals are the $95 \%$ confidence intervals plotted using standard errors that are clustered at the constituency level. 
Figure 5

Effect of Electing Criminally Accused Politicians by Year in Power

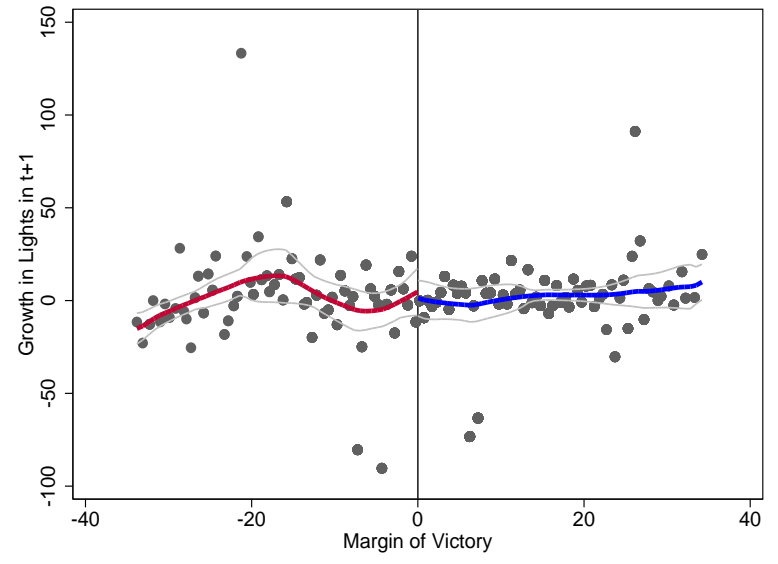

(a) Growth in Lights in $t+1$

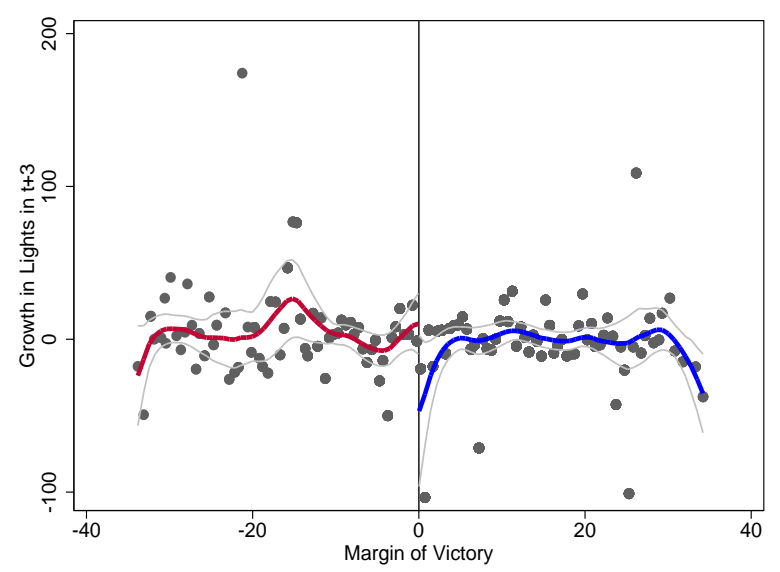

(c) Growth in Lights in $t+3$

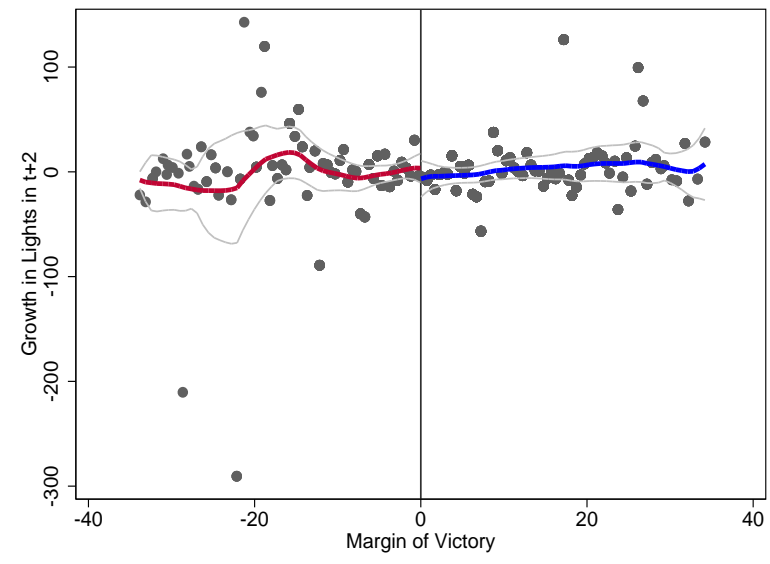

(b) Growth in Lights in $t+2$

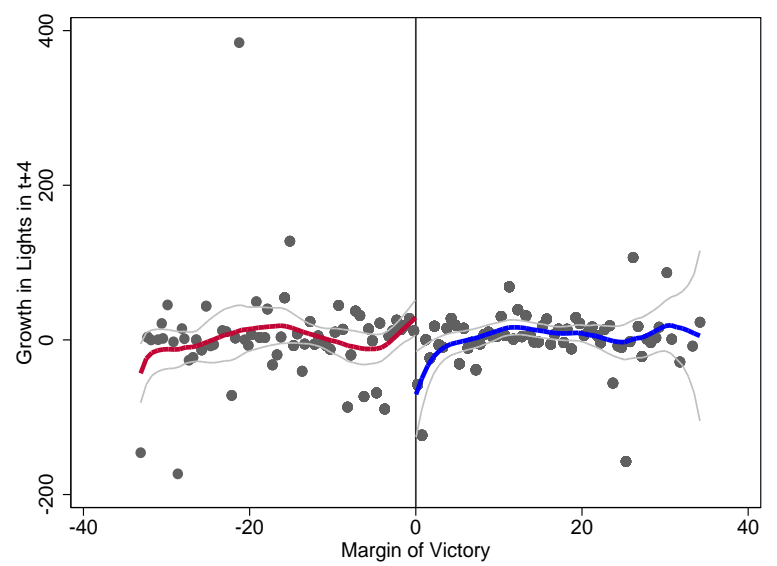

(d) Growth in Lights in $t+4$

The forcing variable is the margin of victory of a criminally-accused candidate. Negative values are the difference in the vote shares of a criminally-accused runners-up and a non-accused winner. Positive values are the differences in the vote shares of a criminally-accused winner and a non-accused runners-up. Each variable on the y-axis is net of state and year fixed effects. The dots in the scatter plot depict the averages over each successive interval of $0.5 \%$ of margin of victory. The curves are local linear regressions fit separately for positive and negative margins of victory using a triangular kernel and an optimal bandwidth calculator as suggested in Imbens and Kalayanaraman (2012). The confidence intervals are the $95 \%$ confidence intervals plotted using standard errors that are clustered at the constituency level. 


\section{Figure 6}

Effect of Electing Criminally Accused Politicians on Length of Roads Built Annually under PMGSY (in kms)

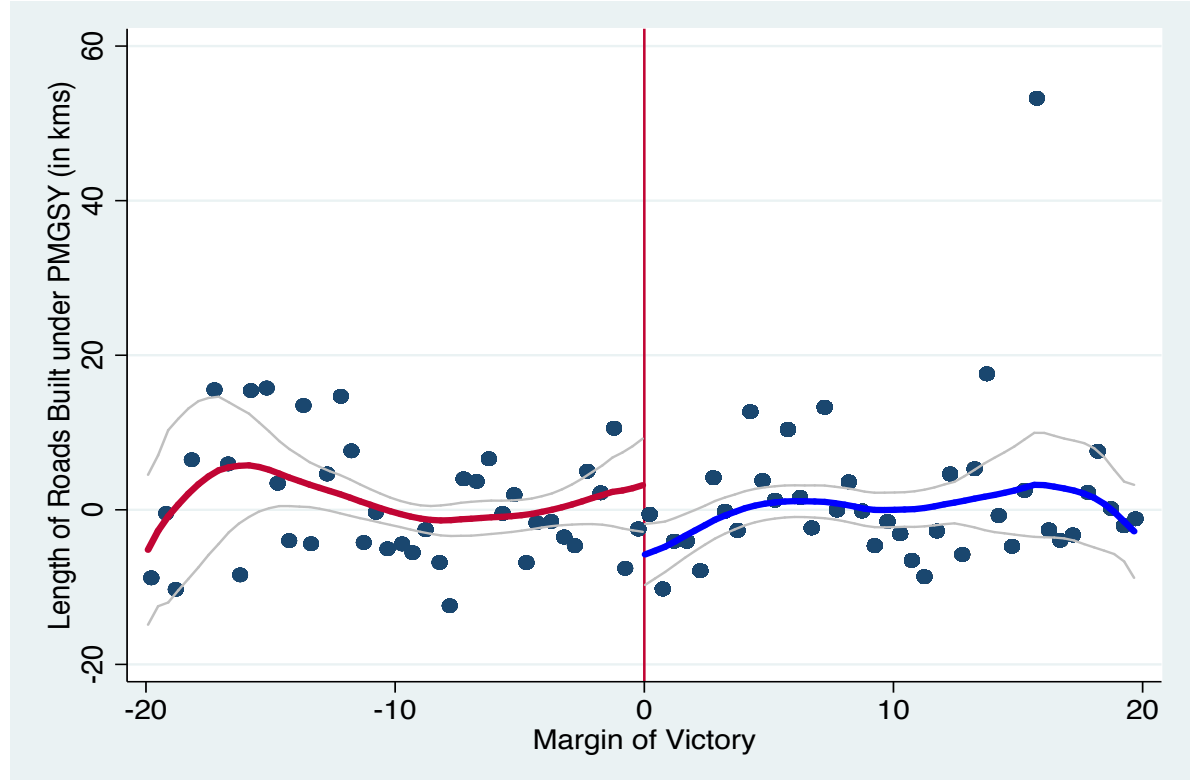

(a) RD Effect

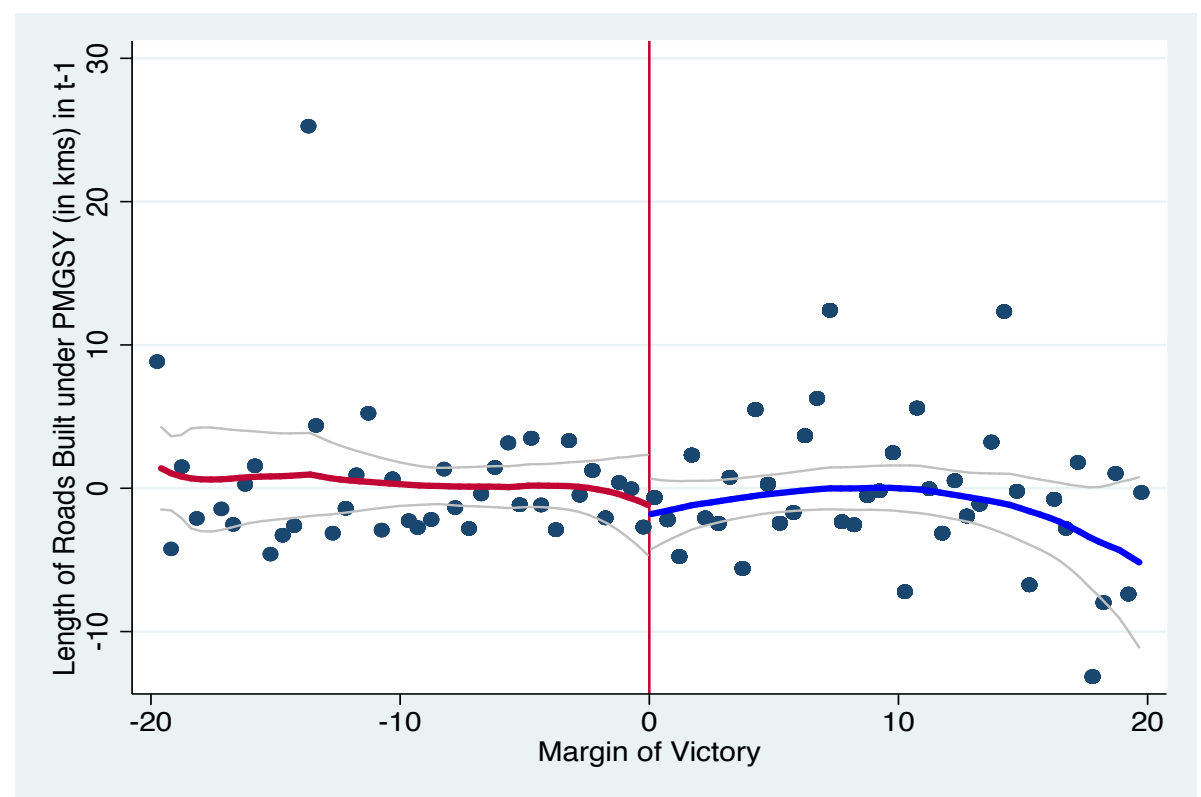

(b) Balance Test

The forcing variable is the margin of victory of a criminally-accused candidate. Negative values are the difference in the vote shares of a criminally-accused runners-up and a non-accused winner. Positive values are the differences in the vote shares of a criminally-accused winner and a non-accused runners-up. The variable on the y-axis is Roads Built Annually under PMGSY (in kms) net of state and year fixed effects. The dots in the scatter plot depict the average number of incomplete road projects over each successive interval of $0.5 \%$ of margin of victory. The curves are local linear regressions fit separately for positive and negative margins of victory using a triangular kernel and an optimal bandwidth calculator as suggested in Imbens and Kalayanaraman (2012). The confidence intervals are the $95 \%$ confidence intervals plotted using standard errors that are clustered at the constituency level. 
TABLE A-1

State Name and Year of Elections

\begin{tabular}{|c|c|c|}
\hline State Name & Number of Constituencies & Election Years* \\
\hline Arunachal Pradesh & 60 & 1999, 2004, 2009 \\
\hline Assam & 126 & 2001, 2006, 2011 \\
\hline Bihar & 243 & $2000, \mathbf{2 0 0 5}, 2010$ \\
\hline Goa & 40 & 2002, 2007, 2012 \\
\hline Gujarat & 182 & 2002, 2007, 2012 \\
\hline Haryana & 90 & 2000, 2005, 2009 \\
\hline Himachal Pradesh & 68 & 2003, 2007, 2012 \\
\hline Jharkhand & 81 & 2005, 2009 \\
\hline Kerala & 140 & 2001, 2006, 2011 \\
\hline Maharashtra & 288 & 1999, 2004, 2009 \\
\hline Manipur & 60 & 2002, 2007, 2012 \\
\hline Meghalaya & 60 & 2003, 2008, 2013 \\
\hline Nagaland & 60 & 2003, 2008, 2013 \\
\hline Odisha & 147 & 2000, 2004, 2009 \\
\hline Punjab & 117 & 2002, 2007, 2012 \\
\hline Tamil Nadu & 234 & 2001, 2006, 2011 \\
\hline Tripura & 60 & 2003, 2008, 2013 \\
\hline Uttar Pradesh & 403 & 2002, 2007, 2012 \\
\hline Uttarakhand & 70 & 2002, 2007, 2012 \\
\hline West Bengal & 294 & 2001, 2006, 2011 \\
\hline Total & 2823 & \\
\hline
\end{tabular}

Notes: Bold years are the first election in each state in which candidates were required to file affidavits detailing criminal and financial background. 
TABLE A-2

Robustness of Main Results

\begin{tabular}{lcccc}
\hline Dependent Variable & \multicolumn{5}{c}{ Growth of Night Lights } \\
\hline & $(1)$ & $(2)$ & $(3)$ & $(4)$ \\
\hline Criminally Accused & $-22.35^{* *}$ & $-19.42^{* *}$ & $-25.65^{*}$ & $-12.25^{* *}$ \\
& $(9.89)$ & $(8.69)$ & $(14.84)$ & $(6.14)$ \\
& & & & \\
& YES & YES & YES & YES \\
Year Fixed Effects & 6.15 & 7.53 & 3.08 & 12.31 \\
Bandwidth Size & 1,550 & 1,757 & 756 & 2,493 \\
No. of observations & \multicolumn{4}{c}{ PANEL B } \\
\hline \multicolumn{1}{l}{ Criminally Accused } & $-22.20^{* *}$ & $-20.82^{* *}$ & $-24.01^{*}$ & $-12.88^{* *}$ \\
& $(8.86)$ & $(8.17)$ & $(13.30)$ & $(5.52)$ \\
& \multicolumn{4}{c}{} \\
Year-State Fixed Effects & YES & YES & YES & YES \\
Bandwidth Size & 6.31 & 7.15 & 3.15 & 12.62 \\
No. of observations & 1,570 & 1,708 & 772 & 2,531 \\
\hline Bandwidth Type & IK (h) & CCT & h/2 & $2 \mathrm{~h}$ \\
Polynomial order of control function & \multicolumn{4}{c}{ Local Linear } \\
\hline \hline
\end{tabular}

NOTES: Standard errors are clustered at the constituency level and given in parentheses. The dependent variable is the residual from the regression of year growth of night lights on state and year dummies. Criminally accused is a dummy variable that is 1 if a criminally accused candidate wins against a non-accused candidate and 0 if criminally accused candidate loses against a non-accused candidate. The RD estimates in column (1)-(4) are on a local linear regression using a triangular kernel. Asterisks denote significance levels $\left(*=.10,{ }^{* *}=.05,{ }^{* * *}=.01\right)$ 
TABLE A-3

Effect of Electing Criminally Accused Politicians by State Characteristics

\begin{tabular}{|c|c|c|c|c|}
\hline Dependent Variable & \multicolumn{4}{|c|}{ Growth of Night Lights } \\
\hline & (1) & $(2)$ & (3) & $(4)$ \\
\hline & \multicolumn{4}{|c|}{ PANEL A: Non-BIMAROU States } \\
\hline Criminally Accused & $\begin{array}{l}-4.46 \\
(3.99)\end{array}$ & $\begin{array}{l}-3.95 \\
(3.61)\end{array}$ & $\begin{array}{l}-7.08 \\
(6.61)\end{array}$ & $\begin{array}{l}-2.01 \\
(2.28)\end{array}$ \\
\hline Bandwidth Size & 9.44 & 10.62 & 4.72 & 18.88 \\
\hline \multirow[t]{2}{*}{ No. of observations } & 1,226 & 1,335 & 651 & 1,910 \\
\hline & \multicolumn{4}{|c|}{ PANEL B: Relatively Developed States } \\
\hline Criminally Accused & $\begin{array}{l}-4.44 \\
(3.71)\end{array}$ & $\begin{array}{l}-4.23 \\
(3.51)\end{array}$ & $\begin{array}{l}-6.12 \\
(5.95)\end{array}$ & $\begin{array}{l}-2.38 \\
(2.12)\end{array}$ \\
\hline Bandwidth Size & 9.67 & 10.37 & 4.84 & 19.34 \\
\hline \multirow[t]{2}{*}{ No. of observations } & 1,243 & 1,306 & 681 & 1,934 \\
\hline & \multicolumn{4}{|c|}{ PANEL C: Low Corruption States } \\
\hline Criminally Accused & $\begin{array}{l}-7.83 \\
(4.87)\end{array}$ & $\begin{array}{l}-6.01 \\
(4.30)\end{array}$ & $\begin{array}{l}-9.88 \\
(6.78)\end{array}$ & $\begin{array}{l}-4.21 \\
(3.23)\end{array}$ \\
\hline Bandwidth Size & 7.28 & 9.22 & 3.64 & 14.57 \\
\hline No. of observations & 1,152 & 1,358 & 611 & 1,789 \\
\hline State and Year Fixed Effects & YES & YES & YES & YES \\
\hline Bandwidth Type & $\mathrm{IK}(\mathrm{h})$ & $\mathrm{CCT}$ & $\mathrm{h} / 2$ & $2 \mathrm{~h}$ \\
\hline Polynomial order of control function & \multicolumn{4}{|c|}{ Local Linear } \\
\hline
\end{tabular}

NOTES: Standard errors are clustered at the constituency level and given in parentheses. The dependent variable is the residual from the regression of state and year dummies. Results displayed in each column come year from a separate regression. Panel A includes the non-BIMAROU states: Arunachal Pradesh, Assam, Goa, Gujarat, Haryana, Himachal Pradesh, Kerala, Maharashtra, Manipur, Meghalaya, Nagaland, Punjab, Tamil Nadu, Tripura, and West Bengal; Panel B includes the Relatively Developed states as ranked by Ministry of Finance: Goa, Haryana, Kerala, Maharashtra, Punjab, Tamil Nadu, and Uttarakhand; and Panel C includes the Low Corruption states as ranked by Transparency International India (TII) on index of corruption: Kerala, Himachal Pradesh, Gujarat, Maharashtra, Punjab, West Bengal, Orissa, and Uttar Pradesh. The RD estimates in columns (1)-(4) are on a local linear regression using a triangular kernel. Asterisks denote significance levels $\left({ }^{*}=.10,{ }^{* *}=.05,{ }^{* * *}=.01\right)$ 
TABLE A-4

Sensitivity Analysis of RD Specification

\begin{tabular}{|c|c|c|c|c|}
\hline \multirow{3}{*}{$\begin{array}{l}\text { Dependent Variable } \\
\text { Type of Accusation }\end{array}$} & \multicolumn{4}{|c|}{ Growth of Night Lights } \\
\hline & \multicolumn{4}{|c|}{ Criminally Accused } \\
\hline & (1) & $(2)$ & (3) & (4) \\
\hline Linear & $\begin{array}{c}-21.73^{* *} \\
(8.83)\end{array}$ & $\begin{array}{c}-20.07^{* *} \\
(8.06)\end{array}$ & $\begin{array}{l}-23.96^{*} \\
(13.28)\end{array}$ & $\begin{array}{c}-12.44^{* *} \\
(5.50)\end{array}$ \\
\hline Quadratic & $\begin{array}{c}-27.03^{* *} \\
(13.46)\end{array}$ & $\begin{array}{c}-27.32^{* *} \\
(12.74)\end{array}$ & $\begin{array}{l}-23.97 \\
(18.14)\end{array}$ & $\begin{array}{c}-22.48^{* *} \\
(9.26)\end{array}$ \\
\hline Cubic & $\begin{array}{l}-20.69 \\
(17.00)\end{array}$ & $\begin{array}{l}-23.35 \\
(16.10)\end{array}$ & $\begin{array}{l}-17.76 \\
(22.00)\end{array}$ & $\begin{array}{c}-28.53^{* *} \\
(12.65)\end{array}$ \\
\hline Quartic & $\begin{array}{l}-22.69 \\
(19.87)\end{array}$ & $\begin{array}{c}-20.2 \\
(18.96)\end{array}$ & $\begin{array}{l}-10.65 \\
(24.03)\end{array}$ & $\begin{array}{c}-26.33^{*} \\
(15.26)\end{array}$ \\
\hline Bandwidth Size & 6.35 & 13.27 & 3.17 & 12.70 \\
\hline No. of observations & 1,581 & 1,728 & 783 & 2,547 \\
\hline State and Year Fixed Effects & YES & YES & YES & YES \\
\hline Bandwidth Type & IK $(\mathrm{h})$ & CCT & $\mathrm{h} / 2$ & $2 \mathrm{~h}$ \\
\hline
\end{tabular}

NOTES: Standard errors are clustered at the constituency level and given in parentheses. Results displayed in each panel-column come from a separate regression that also controls for state and year fixed effects. Criminally accused is a dummy variable that is 1 if a criminally accused candidate wins against a non-accused candidate and 0 if criminally accused candidate loses against a non-accused candidate. The RD estimates in columns (1)-(4) are on a local linear regression using a triangular kernel. Asterisks denote significance levels $\left(*=.10,{ }^{* *}=.05,{ }^{* * *}=.01\right)$

TABLE A-5

Effect of Electing Criminally Accused Politicians using Alternate Dependent Variables

\begin{tabular}{lcc}
\hline \hline Dependent Variable & Log(Night Lights) & Average over Election Term \\
\hline Criminally Accused & $(1)$ & $(2)$ \\
& $-0.91^{* *}$ & $-23.30^{* *}$ \\
& $(0.37)$ & $(9.35)$ \\
\hline Bandwidth Size & 3.16 & 5.71 \\
No. of observations & 779 & 371 \\
\hline State and Year Fixed Effects & YES & YES \\
Bandwidth Type & \multicolumn{2}{c}{ Imbens-Kalyanaraman } \\
Polynomial order of control function & \multicolumn{2}{c}{ Local Linear } \\
\hline \hline
\end{tabular}

NOTES: Standard errors are clustered at the constituency level and given in parentheses. Results displayed in each column come year from a seperate regression. The dependent variable is the residual from the regression of state and year dummies. Log(Night Lights) is the intensity of night lights in levels; and Average Growth over the Election Term is the growth of night lights averaged over the election term of the candidate. The RD estimates in columns (1)-(2) are on a local linear regression using a triangular kernel. Asterisks denote significance levels $\left(*=.10,{ }^{* *}=.05\right.$, $* * *=.01)$ 
TABLE A-6

Controlling for Covariates

\begin{tabular}{lccc}
\hline \hline Dependent Variable & \multicolumn{3}{c}{ Growth of Night Lights } \\
\hline & $(1)$ & $(2)$ & $(3)$ \\
\hline Criminally Accused & $-21.78^{* *}$ & $-21.73^{* *}$ & $-21.27^{* *}$ \\
& $(9.67)$ & $(8.83)$ & $(8.77)$ \\
\hline & \multicolumn{4}{c}{ PANEL B } \\
\hline Criminally Accused & $-21.69^{* *}$ & $-21.97^{* *}$ & $-20.58^{* *}$ \\
& $(9.60)$ & $(8.78)$ & $(8.07)$ \\
\hline Bandwidth Size & 6.35 & 6.35 & 6.35 \\
No. of observations & 1,581 & 1,581 & 1,581 \\
\hline Year Fixed Effects & YES & NO & NO \\
State and Year Fixed Effects & NO & YES & YES \\
Control for covariates & NO & NO & YES \\
Bandwidth Type & Imbens-Kalyanaraman \\
Polynomial order of control function & \multicolumn{3}{c}{ Local Linear } \\
\hline \hline
\end{tabular}

NOTES: Standard errors are clustered at the constituency level and given in parentheses. In Panel A, we do not control for baseline value of log night-lights in the year before election, while in Panel B we control for the baseline value of log night-lights in the year before election. Column (1) includes only year fixed effects; column (2) includes state and year fixed effects; and column (3) includes state and year fixed effects, constituency characteristics: growth of night lights in t-1, growth of night lights in t-2, electorate size, number of voters, whether a constituency was aligned with the ruling party in the state, in the previous election, and whether a constituency is reserved for Scheduled Caste (SC) or Scheduled Tribes (ST); and candidate characteristics: MLA's incumbency status and gender, in the previous election. The RD estimates in columns (1)-(3) are on a local linear regression using a triangular kernel. Asterisks denote significance levels $(*=.10$, $* *=.05, * * *=.01$ 
TABLE A-7

Does Top Coding Matter?

\begin{tabular}{|c|c|c|c|c|}
\hline \multirow[t]{3}{*}{ Dependent Variable } & \multicolumn{4}{|c|}{ Growth of Night Lights } \\
\hline & \multicolumn{4}{|c|}{ PANEL A } \\
\hline & $(1)$ & $(2)$ & $(3)$ & $(4)$ \\
\hline Criminally Accused & $\begin{array}{c}-21.74^{* *} \\
(8.82)\end{array}$ & $\begin{array}{c}-20.23^{* *} \\
(8.11)\end{array}$ & $\begin{array}{l}-23.78^{*} \\
(13.27)\end{array}$ & $\begin{array}{c}-12.35^{* *} \\
(5.51)\end{array}$ \\
\hline Bandwidth Size & 6.36 & 7.25 & 3.18 & 12.73 \\
\hline \multirow[t]{2}{*}{ No. of observations } & 1,567 & 1,710 & 779 & 2,522 \\
\hline & \multicolumn{4}{|c|}{ PANEL B } \\
\hline Criminally Accused & $\begin{array}{c}-21.74^{* *} \\
(8.83)\end{array}$ & $\begin{array}{c}-20.08^{* *} \\
(8.07)\end{array}$ & $\begin{array}{c}-23.95^{*} \\
(13.28)\end{array}$ & $\begin{array}{c}-12.44^{* *} \\
(5.50)\end{array}$ \\
\hline Bandwidth Size & 6.35 & 7.32 & 3.17 & 12.70 \\
\hline No. of observations & 1,581 & 1,728 & 783 & 2,543 \\
\hline State and Year Fixed Effects & YES & YES & YES & YES \\
\hline Bandwidth Type & $\mathrm{IK}(\mathrm{h})$ & $\mathrm{CCT}$ & $\mathrm{h} / 2$ & $2 \mathrm{~h}$ \\
\hline Polynomial order of control function & \multicolumn{4}{|c|}{ Local Linear } \\
\hline
\end{tabular}

NOTES: Standard errors are clustered at the constituency level and given in parentheses. The dependent variable is the residual from the regression of year growth of night lights on state and year dummies. Criminally accused is a dummy variable that is 1 if a criminally accused candidate wins against a non-accused candidate and 0 if criminally accused candidate loses against a non-accused candidate. Panel A drops any observations where the constituency-year pixel average is 63. Panel B drops any constituency in which the average pixel intensity for any year is 63 . The RD estimates in column (1)-(4) are on a local linear regression using a triangular kernel. Asterisks denote significance levels $(*=.10, * *=.05, * * *=.01)$ 
Figure A-7

Share of Criminally Accused Candidates in India
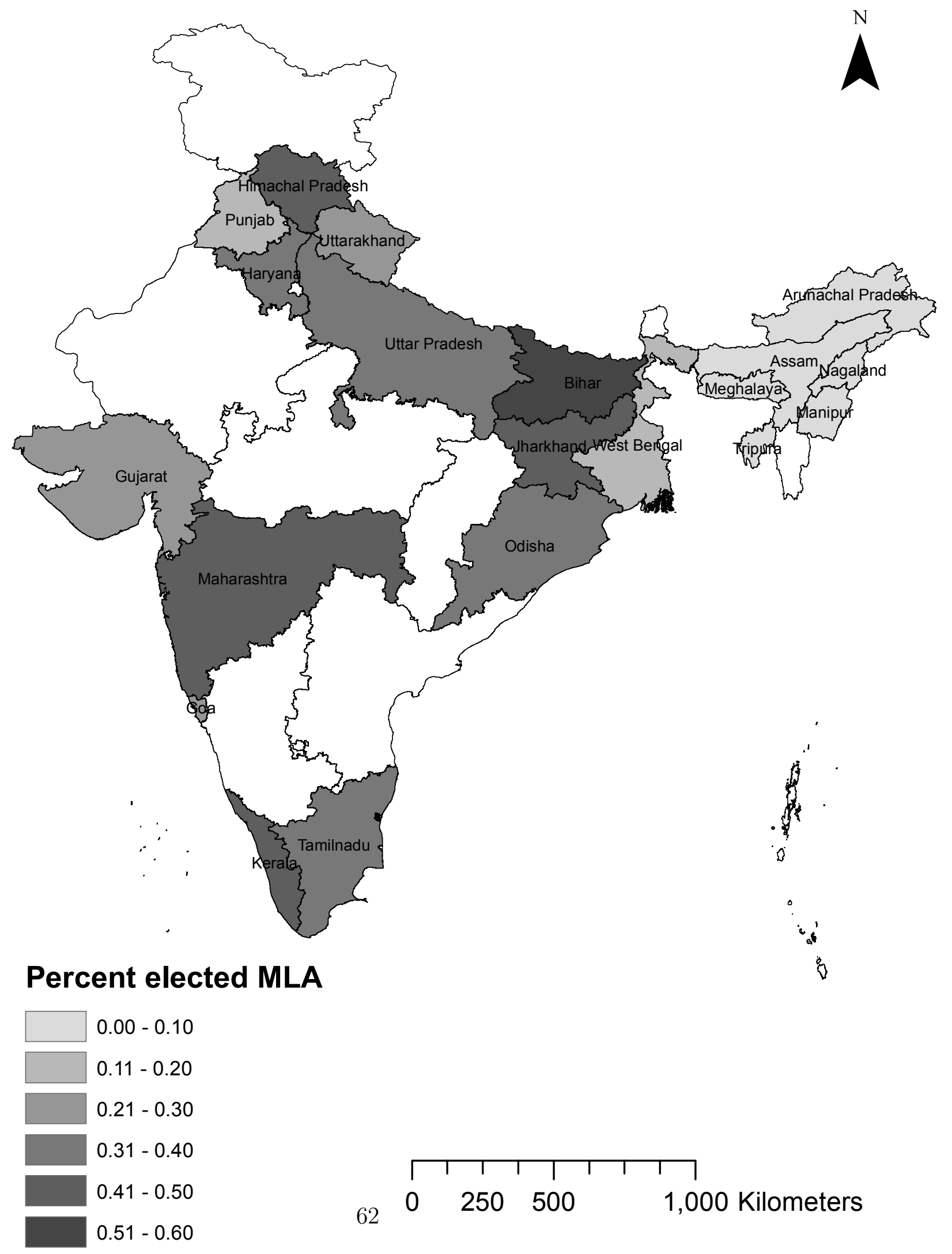